Louisiana State University

LSU Digital Commons

2012

\title{
An examination of the relationship between autism spectrum disorder, intellectual functioning, and social skills in children
}

Kimberly Tureck

Louisiana State University and Agricultural and Mechanical College

Follow this and additional works at: https://digitalcommons.Isu.edu/gradschool_theses

Part of the Psychology Commons

\section{Recommended Citation}

Tureck, Kimberly, "An examination of the relationship between autism spectrum disorder, intellectual functioning, and social skills in children" (2012). LSU Master's Theses. 684.

https://digitalcommons.Isu.edu/gradschool_theses/684

This Thesis is brought to you for free and open access by the Graduate School at LSU Digital Commons. It has been accepted for inclusion in LSU Master's Theses by an authorized graduate school editor of LSU Digital Commons. For more information, please contact gradetd@lsu.edu. 
AN EXAMINATION OF THE RELATIONSHIP BETWEEN AUTISM SPECTRUM DISORDER, INTELLECTUAL FUNCTIONING, AND SOCIAL SKILLS IN CHILDREN

\author{
A Thesis \\ Submitted to the Graduate Faculty of the \\ Louisiana State University and \\ Agricultural and Mechanical College \\ in partial fulfillment of the \\ requirements for the degree of \\ Master of Arts
}

In

The Department of Psychology

By

Kimberly Tureck

B.S., Union College, 2010

August 2012 
LIST OF TABLES

TABLE OF CONTENTS

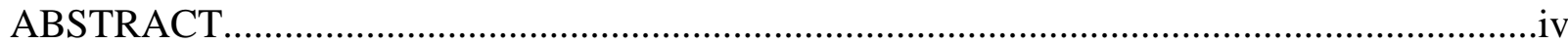

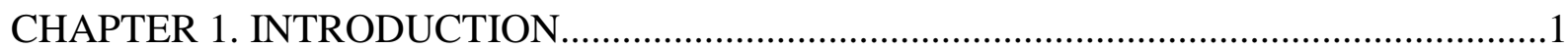

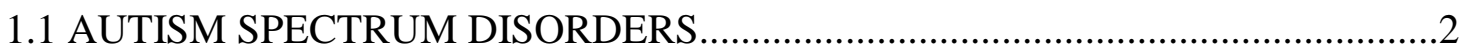

1.1.1 HISTORY OF ASD ................................................................................

1.1.2 CURRENT DIAGNOSTIC CRITERIA FOR ASD ................................

1.1.2.1 AUTISTIC DISORDER.........................................................

1.1.2.2 ASPERGER'S SYNDROME (AS).........................................8

1.1.2.3 PERVASIVE DEVELOPMENTAL DISORDER NOT

OTHERWISE SPECIFIED (PDD-NOS) ............................................

1.1.3 FUTURE DIAGNOSTIC CRITERIA FOR ASD .....................................

1.1.4 CURRENT PREVALENCE OF ASD .................................................11

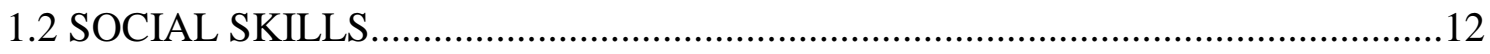

1.2.1 DEFINITION OF SOCIAL SKILLS.................................................12

1.2.2 SOCIALIZATION IN TYPICALLY DEVELOPING CHILDREN...........14

1.2.3 SOCIALIZATION IN CHILDREN WITH ASD......................................18

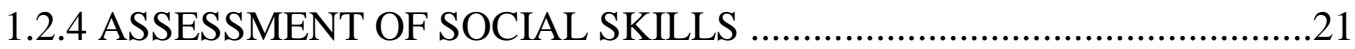

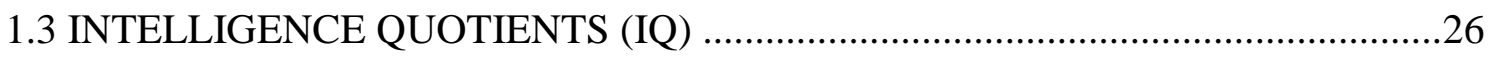

1.3.1 HISTORY OF INTELLIGENCE TESTING.............................................26

1.3.2 INTELLIGENCE TESTING FOR CHILDREN ......................................28

1.3.3 ASSESSMENT AND DIAGNOSIS OF ID.........................................29

1.3.4 PREVALENCE AND ETIOLOGY OF ID..............................................30

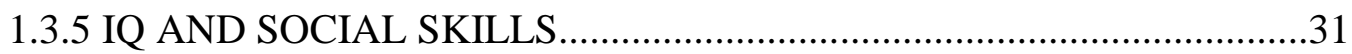

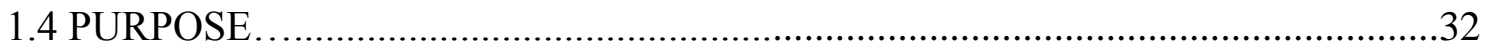

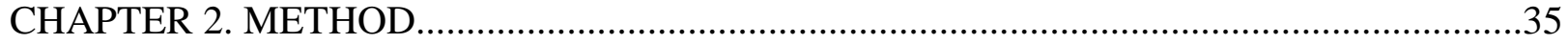

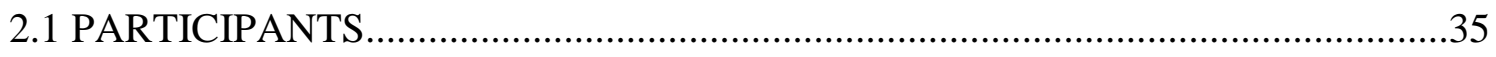

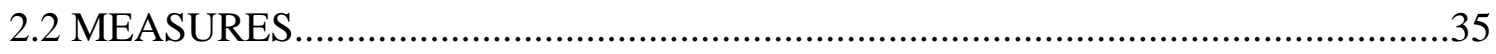

2.3 PROCEDURE

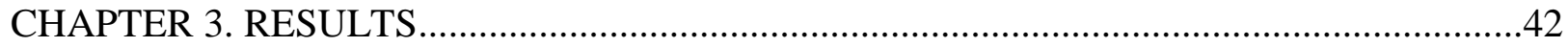

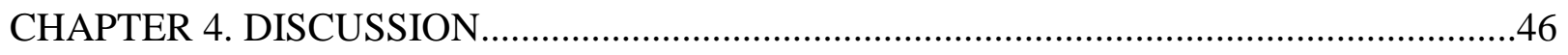

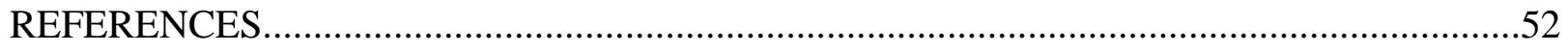

APPENDIX

VITA 


\section{LIST OF TABLES}

1. Demographic Characteristics by Diagnostic Group.............................................................. 42

2. Summary statistics and correlations for Adaptive/Appropriate Social Skills.......................... 43

3. Results of the regression analysis for Adaptive/Appropriate Social Skills.............................. 44

4. Summary statistics and correlations for Hostile/Inappropriate Social Skills.......................... 44

5. Results of the regression analysis for Hostile/Inappropriate Social Skills............................... 45 


\begin{abstract}
Autism spectrum disorders (ASD) are the focus of a vast amount of research due to their recent rise in prevalence. Nonetheless, there is a dearth of research looking at how ASD and IQ scores impact social skills. The present study aimed to extend the literature in this area by evaluating how ASD and IQ scores are related to ratings on a measure of appropriate and inappropriate social skills. Two groups of individuals participated: children without ASD and children with ASD. Two dependent measures of social skills (adaptive/appropriate social skills and hostile/inappropriately assertive social skills) were obtained using the Matson Evaluation of Social Skills for Youngsters-II (MESSY-II). Correlational and multiple regression analyses were conducted to examine the interrelationships between the variables. ASD diagnosis significantly predicted both adaptive/appropriate and hostile/inappropriate social skills. It was negatively and significantly correlated with adaptive/appropriate social skills, indicating that children with ASD tended to have lower scores on the measure of adaptive/appropriate social skills. ASD diagnosis was also positively and significantly correlated with hostile/inappropriate social skills, indicating that children with ASD tended to have higher scores on the measure of hostile/inappropriate social skills. IQ scores were positively and significantly correlated with adaptive/appropriate social skills, indicating that children with higher IQ scores tended to have higher scores on the measure of adaptive/appropriate social skills. The implications of these findings in the context of other research on IQ, ASD, and social skills in children are discussed.
\end{abstract}




\section{CHAPTER 1. INTRODUCTION}

Humans are inherently social creatures (Fiske, 1991). Our society is structured in such a way that we are constantly in situations where we must interact with others to obtain many of the things we need for survival. Thorndike defined social intelligence as "the ability...to act wisely in human relations" (1920, p. 228). Individuals with impairments in social intelligence have greater difficulty navigating these necessary social interactions. The development of appropriate social skills is a critical part of childhood. Those children with an excess of inappropriate social skills or a lack of appropriate social skills may struggle with making friends and have poorer school performance (Matson, Kozlowski, Neal, Worley, \& Fodstad, 2011). Social skills deficits are also associated with a variety of psychological disorders including autism spectrum disorders (ASD; Matson, Dempsey, \& Fodstad, 2009; Matson \& Wilkins, 2007), social anxiety (Wenzel, Graff-Dolezal, Macho, \& Brendle, 2005), depression (Segrin, 2000), attentiondeficit/hyperactivity disorder (ADHD; Wehmeier, Schact, \& Barkley, 2010), and eating disorders (Mallinckrodt, McCreary, \& Robertson, 1995). Conversely, positive social skills are associated with positive relations with others leading to greater psychological well-being (Segrin \& Taylor, 2007). Individuals with ASD experience serious impairments in socialization, and this deficit is independent of their intellectual and adaptive functioning levels (Carpenter, Pennington, \& Rogers, 2002; Matson, Horovitz, Mahan, \& Fodstad, 2010). In this study, the relationship between ASD, IQ scores, and the presence of appropriate or inappropriate social skills will be assessed. First, ASD will be discussed, followed by definitions and measurement of social skills, and then finally a discussion of intelligence testing will follow. 


\subsection{Autism Spectrum Disorders}

\subsubsection{History of ASD}

The term 'autism' was coined by Eugen Bleuler, a Swiss psychiatrist, who was trying to describe the loss of contact with external reality displayed by people with schizophrenia (Bleuler, 1913). The first clinical accounts of the disorder we label as autism today were provided by Leo Kanner in 1943 when he published a detailed account of 11 children with a common clinical presentation. The common characteristics he noted were deficits in socialization, difficulties in communicating effectively, and a strict insistence on sameness. Postulating that one single condition accounted for these features, Kanner coined the term 'early infantile autism' in 1944 (Kanner, 1965). The primary characteristic shared by all these children in Kanner's (1943) opinion was what he described as "extreme autistic aloneness," or a seeming inability to effectively interact with other people. Kanner (1943) noted that all 11 children preferred to isolate themselves and had an inability to form typical relationships. The children had no desire to play with others, generally ignored attempts by others to interact with them, and seemed to be in their own world most of the time. This withdrawal behavior could be traced back to infancy, so Kanner (1943) inferred that environmental factors such as parental interaction could not fully account for the social withdrawal. He therefore surmised that genetics must be somehow involved. Kanner (1943) identified autism as separate from the features seen in children with schizophrenia, because the socially isolative behavior was present from birth. Conversely, those people with schizophrenia exhibited a period of normal socialization followed by regression. Also, children with autism demonstrate some connection with the external world, although they tend to be fixated on objects rather than people (Kanner, 1965). With both Kanner and Bleuler 
using the term autism, there was confusion in the field for years. As a result, many professionals assumed infantile autism was a form of childhood schizophrenia.

Of the 11 children Kanner examined in depth, three were mute and the other eight had nonfunctional language (e.g., repeating phrases, pronoun reversal, and only understanding words in a situation specific manner). This deficit in communication abilities is the second core feature of the disorder. Kanner (1943) also noted that these children demonstrated stereotypic behaviors and a strict insistence on sameness. The children had a predilection to line up objects and perform daily routines in a highly ritualized manner. When something interfered with the children's routines, they had a tendency to engage in challenging behaviors. Aside from challenging behaviors, these children also exhibited stereotypic behaviors including repetitive manipulation of objects and/or repetitive body movements.

Although Kanner clearly described early infantile autism as its own disorder, in the original version of the Diagnostic and Statistical Manual (DSM-I; APA, 1952) the term childhood schizophrenia was still used to describe this cluster of features. As late as 1978, the International Classification of Diseases, Ninth Edition (ICD-9; WHO, 1977) still placed autism with the childhood psychotic disorders, despite research clearly delineating the differences between autism and schizophrenia (Kolvin, 1971; Rutter \& Bartak, 1971). Some of the core features that delineate between the two disorders are the development of language and cognitive skills (normal in those with schizophrenia, but abnormal in autism) and the experience of hallucinations or delusions (only present in those with schizophrenia) (Kolvin, 1971). Rutter and Bartak (1971) added greater support to this conclusion when they published some other key differences between autism and schizophrenia. First, they noted that the two disorders differed in terms of distribution between the two genders, with autism more common in males and no 
gender difference observed in the rate of schizophrenia. Second, they noted that family history of psychotic disorders was more common in individuals with schizophrenia than those with autism. Another difference is that individuals with schizophrenia tend to have higher intellectual functioning levels than those with autism. Finally, a major difference between the two disorders is age of onset. To highlight this difference, Rutter and Bartak (1971) added onset of the disorder by 30 months of age to Kanner's (1943) original three criteria. They also excluded stereotypic behaviors from the list of diagnostic criteria, because these are also characteristic of individuals with intellectual disability who do not present with any of the other features of autism. Instead, they highlighted the presence of compulsive behavior and insistence on sameness (e.g., rituals, attachment to unusual objects, and resistance to change).

Rutter solidified his conceptualization of autism in 1978. It remains one of the most important definitions of the disorder (Matson \& Minshawi, 2006; Volkmar \& Klin, 2005). His definition included four criteria that needed to be met for a diagnosis of autism: (1) impairments in socialization, (2) delay in language development, (3) insistence on sameness, and (4) onset by 30 months of age. Although this definition is similar to the one put forth by Bartak (Rutter \& Bartak, 1971), Rutter (1978) added some important qualifiers. His definition specified that each child should be evaluated for social deficits, language delay, and ritualized behavior in terms of his or her individual cognitive functioning level. Rutter (1978) also advocated for medical and neurological rule outs in the diagnostic process.

That same year, the National Society for Autistic Children (NSAC), published a competing definition for the disorder (Ritvo \& Freeman, 1977, 1978). Their definition consisted of five diagnostic criteria: (1) language, cognition, and communication delays, (2) odd reactions to sensory stimuli, (3) abnormal rate of development, (4) impaired ability to relate to objects, 
events, and people, and (5) age of onset before 30 months. Part of the reason that these definitions differed was that the authors had incompatible goals. The authors of the NSAC definition were motivated by a desire to gain more support from public and private institutions to fund research and treatment projects. Conversely, Rutter (1978) was interested in publishing his empirical research findings to clarify contradictory evidence in the literature (Matson \& Minshawi, 2006).

Infantile autism was finally given its own section in the Diagnostic and Statistical Manual, Third Edition (DSM-III; APA, 1980). The APA based its diagnostic criteria on empirical research, so it was fairly consistent with the definition developed by Rutter in 1978 (Volkmar \& Klin, 2005). The DSM-III also included a larger section titled Pervasive Developmental Disorders (PDD), which subsumed all developmental disorders with childhood onset (Volkmar \& Klin, 2005). The name infantile autism was updated to Autistic Disorder in the revision of the DSM-III (DSM-III-R; APA, 1987), and the criteria were changed to require a person to meet 8 of the 16 symptoms to receive a diagnosis of Autistic Disorder. More specifically, a person had to meet criteria in each of the three core areas of impairment (socialization, communication, and restricted repetitive behaviors and interests). The DSM-III-R eliminated age of onset as a diagnostic criterion to allow people who developed autistic symptoms after 30 months to qualify for the diagnosis. This led to over diagnosis of the disorder in some cases (Spitzer \& Siegel, 1990).

The criteria for autism was further refined in the Diagnostic and Statistical Manual, Fourth Edition (DSM-IV; APA, 1994). An attempt was made to coordinate the diagnostic criteria with the International Classification of Diseases, Tenth Edition (ICD-10; WHO, 1992). The number of criteria needing to be met was reduced to six, although this still required 
endorsements in the three core areas of impairment. The DSM-IV also re-instituted age of onset as a criterion, but changed the age from 30 months to 36 months (APA, 1994).

Asperger's syndrome (AS) was first described by Hans Asperger, an Austrian physician, who published a series of case studies on highly intelligent children exhibiting some peculiar impairments (Asperger, 1944). Without any knowledge of the work being done by Kanner (1943), Asperger (1944) named this new disorder 'autistic psychopathology' due to the severity of the social impairments in these children. He conceptualized it as a type of personality disorder (Asperger, 1944). Similar to Kanner's (1943) findings, Asperger cited the tendency for the cluster of symptoms to run in families as evidence of a genetic basis for the disorder. Asperger described five main symptoms for individuals with the disorder: (1) impairments in socialization, (2) deficits in nonverbal communication, (3) stereotypic behaviors, (4) insistence on sameness, and (5) lack of a sense of humor (Asperger, 1944). He pinpointed impairments in social interactions as the core feature of the disorder.

AS became more widely recognized following Wing's (1981) publication of a detailed description of the disorder that had been previously referred to as autistic psychopathology (Frith, 2004; Howlin, 2006; Matson \& Boisjoli, 2008). Wing (1981) described nine main characteristics that make up AS: (1) socialization deficits (e.g., social withdrawal and lack of interest in play), (2) abnormal speech (e.g., odd tone, pedantic speech, and stereotyped speech), (3) deficits in nonverbal communication (e.g., odd gestures, lack of facial expression, and lack of eye contact), (4) stereotypic behaviors, (5) repetitive activities, (6) poor motor coordination, (7) insistence on sameness, (8) decreased empathy, and (9) circumscribed interests (i.e., an abnormal fixation on a certain topic). The disorder is more prevalent in males, and Wing (1981) described 
the disorder as a milder version of autism. This idea of the disorders as falling on a spectrum from least severe to most severe was predictive of future directions in the diagnosis of ASD.

There are two other disorders subsumed under the heading of Pervasive Developmental Disorders that will not be examined in this study. Rett's syndrome (RTT) is defined as rapid cognitive and linguistic declines along with slowed motor movement and decreased growth of head circumference (Hagberg, Aicardi, Dias, \& Ramons, 1983). These declines follow a period of seemingly typical development and only occur in females, providing evidence for a genetic etiology (Hagberg et al., 1983). The other PDD not considered in this study is Childhood Disintegrative Disorder (CDD). Individuals with CDD exhibit a period of typical development up until age 3 or 4 years and then experience a regression of communication and social skills (Volkmar \& Klin, 2005). These children also develop stereotypic behaviors during the period of regression (Rutter, 1972).

\subsubsection{Current diagnostic criteria for ASD}

The most recent version of the Diagnostic and Statistical Manual for Mental Disorders is the Fourth Edition-Text Revised (DSM-IV-TR; APA, 2000), and it includes the same diagnostic criteria as the previous version. The $D S M-I V$-TR includes five subgroups under the larger category of PDD: Autistic Disorder, Asperger's Syndrome, Pervasive Developmental Disorder Not Otherwise Specified (PDD-NOS), Rett Syndrome, and Childhood Disintegrative Disorder.

\subsubsection{Autistic Disorder}

For an individual to meet criteria for Autistic Disorder, he or she must exhibit six or more of the diagnostic items. More specifically, at least two of these six endorsed items must come from the socialization domain, and at least one endorsed item must come from each the communication domain and the restricted, repetitive and stereotyped patterns of behavior, 
interests, and activities. The socialization domain contains the following items: (1) impairment in non-verbal behaviors (e.g., eye contact, facial expressions, and gestures), (2) inability to develop appropriate peer relationships, (3) impaired desire to share enjoyment and interests with others, and (4) deficits in reciprocal interacting. Items in the communication domain include: (1) absent or delayed verbal communication, (2) clearly impaired ability to initiate and/or maintain conversations, (3) repetitive or idiosyncratic language usage, and (4) impairments in pretend play. Items in the restricted, repetitive and stereotyped domain include: (1) preoccupation with one or more stereotyped or restricted interests that is abnormal in focus or intensity, (2) strict adherence to nonfunctional rituals or routines, (3) repetitive motor movements, and (4) a fixation on parts of objects. These impairments must be present prior to three years of age, and the symptoms cannot be better accounted for by a diagnosis of CDD or RTT.

\subsubsection{Asperger's Syndrome (AS)}

The criteria for AS in the DSM-IV-TR (APA, 2000) dictates that an individual display typical development in cognition, language, and adaptive functioning. Impairments must be evident in the areas of socialization and restricted repetitive and stereotyped patterns of behavior. Items in both of these areas are consistent with the criteria for Autistic Disorder.

\subsubsection{Pervasive Developmental Disorders Not Otherwise Specified (PDD-NOS)}

The DSM-III (APA, 1980) was the first version to include a diagnosis of atypical autism. This category was created to account for the great number of individuals who did not have the severity of symptoms required to meet criteria for a PDD diagnosis but who exhibited most of the same impairments. The APA (1987) began referring to all sub-threshold diagnoses as 'not otherwise specified' (NOS) in the DSM-III-R, allowing for the diagnostic label PDD-NOS. A diagnosis of PDD-NOS in the DSM-III-R required that an individual demonstrate impairments in 
socialization and communication, but did not require the presence of repetitive and stereotyped patterns of behaviors (APA, 1987). The diagnostic criteria for PDD-NOS were altered slightly in the DSM-IV, with an individual needing to demonstrate impairment in only one of the three core areas of impairment (APA, 1994). For an individual to meet criteria for PDD-NOS in the DSM$I V$-TR (APA, 2000), he or she needs to demonstrate impairments in socialization as well as impairments in either communication or restricted repetitive and stereotyped behaviors. The items for these areas are consistent with those for Autistic Disorder. The individual must also be evaluated to rule out the alternative diagnoses of a specific PDD, Schizophrenia, Schizotypal Personality Disorder, or Avoidant Personality Disorder.

\subsubsection{Future diagnostic criteria for ASD}

The DSM-V is currently in the works and set to be published by the APA in May 2013. The latest manual has numerous proposed changes to the diagnostic criteria for ASD and is a source of controversy among researchers and clinicians in the field (Wing, Gould, \& Gillberg, 2011). The proposed criteria reduces the triad of impairments to only two, combining socialization and communication into one factor while keeping restricted behavior as the other factor (APA, 2010). They are combining socialization and communication because communication is itself a social behavior. To meet criteria for Autism, individuals must demonstrate socialization and communication deficits as evinced by all three of the following: (1) deficits in social and emotional reciprocity, (2) deficits in nonverbal communication, and (3) impaired ability to develop and maintain relationships appropriate to their developmental level. They must also demonstrate restricted, repetitive patterns of behavior, interests, or activities as evinced by two of the following four criteria: (1) stereotyped or repetitive speech, object usage, or motor movements, (2) strict adherence to routines, insistence on sameness, or ritualized 
behavior, (3) fixation on certain topics that is abnormal in intensity or focus, and (4) abnormal reactivity to sensory input or fixation on specific sensory portions of the environment. As it stands currently, the DSM-V does not have a proposed age cutoff. However, it will require that symptoms are present in early childhood, even if they do not fully manifest until later in the child's development.

The second major change in the DSM-V will be the removal of subgroups, with all forms of ASD being subsumed under the title Autism (Wing et al., 2011). The APA (2010) argued that autism should be a single diagnostic label because it involves a common set of behaviors and features. They propose that clinical specifiers (e.g., severity and verbal ability) can be used to further describe each individual's clinical presentation. The DSM-V will include three severity levels for ASD: level 1 (requiring support), level 2 (requiring substantial support), and level 3 (requiring very substantial support). Those at level 1 have noticeable impairments in social communication and exhibit rituals and repetitive behaviors (RRBs). Those at level 2 have marked impairments in verbal and nonverbal communication, limited social interaction, and RRBs that interfere with functioning across contexts. Finally, those at level 3 have severe socialization deficits that cause impaired functioning and RRBs that completely interfere with functioning in all aspects of their lives.

Eliminating the subgroups is a source of great controversy, especially among individuals with AS. Being labeled as autistic is more stigmatizing in our society than a label of AS. Research also suggests that there are essential differences in the core features of AS and Autistic Disorder such as a lack of impaired communication or cognitive delay in individuals with AS (Kaland, 2011). Additionally, there is some ambiguity in the DSM-IV-TR (APA, 2000) as to the differences between AS and high-functioning autism (HFA) that needs to be further clarified in 
the DSM-V (Bartlett, Armstrong, \& Roberts, 2005). HFA refers to individuals who meet most of the criteria for Autistic Disorder, but have normal intellectual functioning and a history of language delay (Zalla, Barlassina, Buon, \& Leboyer, 2011). Individuals with AS perform better on verbal IQ tests than those with HFA, so this could serve as one diagnostic criterion (Kaland et al., 2002). Recent brain imaging studies have demonstrated that there are differences in brain structures between individuals with AS and Autistic Disorder (Jou, Minshew, Keshavan, \& Hardan, 2010). There is no research at the present to link AS and Autistic Disorder biologically, because few genetic studies have been done on individuals with AS. Thus, it may be premature to group the two disorders under one diagnostic label in the DSM-V (Kaland, 2011)

\subsubsection{Current prevalence of ASD}

ASD now afflicts 63.7 of every 10,000 children, which translates to one in 150 children in the United States diagnosed with ASD (Fombonne, 2009). This statistic has led many to classify ASD as an epidemic in the United States. There has been a subsequent increase in knowledge about the disorder among the public, "for whom autism seems to hold a special fascination" (Schreibman, 2005). Numerous explanations have been proposed to account for the increase in prevalence of ASD in the past two decades (Wing \& Potter, 2002). One factor clearly contributing to the increase in prevalence is changes in diagnostic criteria. When autism was first described by Kanner (1943), the diagnosis applied to a much narrower group of individuals than those who are currently diagnosed under the spectrum of autistic disorders (Wing \& Gould, 1979). Another factor that is central to the increase in prevalence is the acknowledgment that ASD can be comorbid with other conditions including intellectual disability and other developmental, psychological, or physical disabilities (Wing \& Potter, 2002). 
Improved awareness of the condition means that pediatricians are far more likely to diagnose a child with ASD today than they would have been three decades ago (Fombonne, 2009) PDD-NOS is the most prevalent PDD, and it occurs at a rate of 37.1 per 10,000 people (Fombonne, 2009). This is frequently the case in other classes of psychological disorders as well. People often do not meet all diagnostic criteria to warrant the full diagnosis when they present with subthreshold impairments, so clinicians label them as 'not otherwise specified' (Angst, 2009). Autistic Disorder is second in prevalence and occurs at a rate of 13 to 19 per 10,000 people, while AS occurs less frequently at a rate of 9.5 per 10,000 people (Howlin, 2006). Researchers have long noted that PDD has features associated with other disorders, which must always be ruled out before a diagnosis of PDD can be given in accordance with $D S M-I V-T R$ criteria. There are also numerous conditions that are often comorbid with ASD including intellectual disability (ID), epilepsy, and other psychopathologies. An estimated 75\% of people with ASD also have ID (Matson \& Nebel-Schwalm, 2007). In addition, an estimated $25 \%$ of people with ASD have comorbid epilepsy (Howlin, 2006; Volkmar, \& Klin, 2005).

Other commonly comorbid disorders include: anxiety disorders (Ming, Brimacombe, Chaaban, Zimmerman-Bier, \& Wagner, 2008; Tsakanikos et al., 2006), affective disorders (Ghaziuddin, Ghaziuddin, \& Greden, 2002; Ming, et al., 2008; Tsakanikos et al., 2006), ADHD (Montes \& Halterman, 2007), and certain personality disorders (Tsakanikos et al., 2006).

\subsection{Social Skills}

\subsubsection{Definition of social skills}

Researchers have long debated how to most accurately define social skills in children. Some professionals have determined that it may be simpler to define specific aspects of social skills rather than attempting to make one universal definition (McClelland \& Scalzo, 2006). 
Matson and Ollendick (1988) defined social skills broadly as the ability to interact appropriately with others in social situations. Howlin (1986) was more specific and described social behavior as "the ability to relate to others in a mutually reinforcing and reciprocal fashion and to adapt social skills to the varying demands of interpersonal contexts" (p. 103). Social behavior in children can be divided into two broad categories: interpersonal social skills, which are needed for relating to others, and learning-related social skills, which are needed for success in academic settings (Cooper \& Farran, 1988). Within the category of interpersonal social skills in children, researchers have focused on peer acceptance and social validity. Dodge and colleagues (2003) studied peer acceptance in children and found that poor social skills leading to rejection by peers during a child's early school years was a significant predictor of antisocial behavior during adolescence for children who already demonstrated aggressive behavior. Social validity refers to the behaviors that are necessary for acceptance by peers, parents, and teachers, which can be further broken down into social competence and social skills. Social competence is a general assessment of a child's performance in social situations, whereas a social skill is a child's ability to perform a social task proficiently (McFall, 1982). By intervening in early childhood when a social skill deficit is first identified, clinicians can work with children to increase their social validity (McClelland \& Scalzo, 2006).

Aside from interpersonal skills, children also need to develop appropriate learning-related social skills. These include a number of skills (e.g., responsibility, independence, and selfregulation behaviors) that are needed for adaptation to learning situations and successful performance in school (McClelland \& Scalzo, 2006). Poor social skills in these areas can negatively impact school performance as early as kindergarten. They are also related to a number of characteristics: lower IQ scores, externalizing behaviors, and medical problems (e.g., 
speech and hearing) (McClelland, Morrison, \& Holmes, 2000). This poor start can continue through elementary school and lead to long-term academic difficulties.

More generally, the development of appropriate social skills contributes to better overall psychological functioning in adulthood. The acquisition of social skills can be broken down into stages that build upon each other, with early skills necessary for the development of later skills. If a young child fails to develop some of the more basic social skills (e.g., eye contact, facial expressions), then he or she will likely struggle to develop more advanced skills (e.g., cooperation with others, reading nonverbal cues) (Dawson \& Galpert, 1986). The following two sections will provide an overview of social skills in typically developing children and then elucidate some of the differences seen in children with autism spectrum disorders (ASD).

\subsubsection{Socialization in typically developing children}

Social interactions are critical to all aspects of development. Even as newborns, people are able to process faces differently from other stimuli and show a clear preference for human faces compared to other objects in their environment (Grossman \& Johnson, 2007). At around two months of age, infants begin to distinguish their mother's face from other people's faces, smile at others, and show a preference for direct eye contact (Farroni, Massaccesi, Menon, \& Johnson, 2007; Sirios \& Jackson, 2007). These social behaviors were demonstrated in a study by Farroni and colleagues (2007) when they compared infants' ability to recognize faces with direct eye contact versus faces with indirect eye contact. If an infant does not develop appropriate eye contact this can lead to impairments in the development of communication and negatively impact social interactions later in life (Grossman \& Johnson, 2007). Appropriate eye contact is especially critical in infants, because they are still nonverbal. Eye contact can be used to develop a sense of intimacy with another person, or more often, to shift another person's attention to a 
point of interest (Farroni et al., 2007). Typically developing infants should be consistently engaging in appropriate eye contact by six months old (Sirios \& Jackson, 2007).

Around this same time, infants begin being able to produce and interpret facial expressions. There is a debate among researchers as to how early this skill should be present in typically developing infants. Grossman and Johnson (2007) stated seven months as the standard while Thomas, De Bellis, Graham, and LaBar (2007) stated that infants can understand the meaning behind facial expressions as early as four months of age. Interpreting facial expressions is a critical nonverbal communication skill, and it allows infants to conjecture as to other's intentions, emotional states, and perhaps even their future behavior (Grossman \& Johnson, 2007; Striano \& Vaish, 2006). In a recent study, $84 \%$ of mothers reported that their infant could produce clear expressions of interest and joy by just one month of age (Feldman, 2006).

Once the infant has developed the ability to produce facial expressions, at around six to nine months of age, other social milestones should appear in the following months. The infant should begin to engage in social smiling, with this smiling preferentially directed at the infant's mother starting at 18 months of age (Feldman, 2006). Then around 12 months old, infants should be able to communicate needs with gestures and imitate actions performed by others (Carpenter, et al., 2002). Researchers investigated nine main social behaviors in infants every month from 9 to 15 months of age (Carpenter, Nagell, Tomasello, Butterworth, \& Moore, 1998). The first behaviors to emerge were reactions to social obstacles, proximal declarative gestures, and joint attention. The next behaviors to emerge were imitation of instrumental acts, point following, imitation of arbitrary acts, and gaze following, which all require the infant to track an adult's attention to more distant stimuli. The last social behaviors to develop during this period 
were imperative gesturing and declarative pointing, which require the infant to direct an adult's attention to proximal/distal stimuli.

Once infants become more aware of their social environments they begin to meaningfully interact with the people around them. Typically, empathy for others begins to develop around 24 months of age (Feldman, 2006). This ability to understand others allow children to form healthy attachments and social relationships with others. Attachment style is evident in infants based on the degree of proximity the child wants to his/her mother and/or caregiver (Dissanayake \& Sigman, 2001). There are four main types of attachment (i.e., Secure, Avoidant, Ambivalent, and Disorganized-disoriented). Researchers have found that $66 \%$ of North American children have no difficulty forming secure attachments to their caregivers (Feldman, 2006). Infants also demonstrate social reciprocity, which is a behavioral expression that "invites further responses from parents and other caregivers" (Feldman, 2006, p. 207).

During childhood, play skills are critical for developing appropriate peer interaction. These skills are typically acquired by age two, and infants as young as 6-10 months engage in play behaviors (e.g., sharing toys, mutual object manipulation, and physical imitation using toys) (Stone \& La Greca, 1986). Through these playful interactions, children begin to develop more advanced social skills and demonstrate friendship-seeking behavior. Making friends requires a number of positive social skills including: affect recognition, self-regulation, perspective-taking ability, and empathy for others (Gifford-Smith \& Brownell, 2003).

Friendships are defined as voluntary, personal, dyadic relationships based on mutual trust and cooperation (Gifford-Smith \& Brownell, 2003). Throughout development, children demonstrate different levels of friendship. Preschool-aged children develop friendships by engaging in coordinated play, especially imaginative play in dyads or small groups (Gifford- 
Smith \& Brownell, 2003). School age children begin to develop friendships based on shared interests, which is indicative of them developing interpersonal awareness. Children of this age engage in game playing and dynamic conversations with their friends (Gifford-Smith \& Brownell, 2003). Often in late childhood and early adolescence children develop one single, favored peer who they refer to as their best friend. This close friendship is critical in the development of social skills including empathy and concern for the wellbeing of others. These skills are important for adult relationships (Sullivan, 1953). By adolescence, friendships are based on intimate exchanges featuring openness and honesty (Parker \& Gottman, 1989).

The absence of appropriate social skills or presence of hostile/inappropriate social skills becomes pronounced once children reach elementary school. There is a high level of correlation between children being rejected by their peers and who demonstrate aggressive behavior (Dodge, 1983). This link between aggression and rejection is different for boys than for girls, with boys demonstrating more overt aggression (e.g., verbal and physical) while girls demonstrate more relational aggression (e.g., exclusion, negative gossip, and verbal threats) (Gifford-Smith \& Brownell, 2003). Researchers are unclear as to the causal relationship between rejection and aggression. It could be that rejection causes a child to become aggressive or that the presence of aggressive/hostile behavior leads peers to reject certain children. Some rejected children are not aggressive, but are instead described by their peers as socially awkward, incompetent, or frequently engaging in odd behaviors (Bierman, Smoot, \& Aumiller, 1993). These children demonstrate non-hostile, but still inappropriate, social skills including social withdrawal, passive behavior, avoiding eye contact, and failing to respond when others initiate interactions.

On the opposite end of the spectrum from rejected children are popular children, who typically demonstrate above average levels of appropriate/adaptive social skills (Gifford-Smith 
\& Brownell, 2003). Popular children tend to be described as possessing positive social skills such as cooperation, helping behavior, associative play, and a tendency to initiate conversations (Coie, Dodge, \& Kupersmidt, 1990). Another group that shares aspects of both rejected children and popular children is controversial children, who are both liked and disliked by their peers. These children are often perceived as arrogant or aggressive by their peers leading to ambiguous interactions (Gifford-Smith \& Brownell, 2003). Some correlational data suggest that controversial children have higher intellectual abilities than their rejected peers (Newcomb, Bukowski, \& Pattee, 1993). This higher cognitive level and engagement in some positive peer relationships may act as a buffer against the negative psychological outcomes associated with peer rejection. This lends support for the notion that individuals with higher intellect have more positive social skills.

\subsubsection{Socialization in children with ASD}

Deficits in socialization are one of the three core features of ASD, and the abnormal development of social skills is evident from infancy (Kanner, 1943; Volkmar, Carter, Grossman, $\&$ Klin, 1997). The first signs of abnormality are a failure of the infant to develop social smiling and eye contact (Rutter, 1978). This failure to develop appropriate eye contact hinders the acquisition of joint attention (i.e., pointing out things of interest to caregiver). Failure to acquire joint attention is a main focus of research on ASD and is often singled out as a precursor to other deficits that typify ASD (Volkmar et al., 1997). Without joint attention, children have difficulty engaging in cooperative play or developing any reciprocal relationships. For this reason, many children with ASD prefer isolative, stereotyped play to social interaction. There is also typically an absence of pretend play and a disinterest in playing with peers (Howlin, 1986). 
Children with ASD exhibit impairments in social interaction related to speech abnormalities, linguistic conventions, and failure to initiate interpersonal interactions. Often children with ASD demonstrate poor imitation of both nonverbal and verbal communication. This hinders their ability to develop the appropriate communication skills necessary for social interaction (Dawson \& Adams, 1984). Subsequently, individuals with ASD are at an increased risk of being rejected by their peers and often experience social isolation (White, Keonig, \& Scahill, 2007). Children with ASD may desire more social interaction, but display difficulties in discerning when self-disclosure is appropriate and how much information they should share (Wilkins \& Matson, 2007). Children with ASD also have greater difficulty discriminating social cues than children at the same level of intellect (Hobson, 1986). They may demonstrate impairments in social pragmatics (e.g., forgetting to take turns in conversations and perspective taking), speech abnormalities (e.g., odd inflection and unusual pitch), and a tendency to perseverate on certain topics (White et al., 2007). Researchers are unsure as to the exact reasons why children with ASD fail to develop appropriate social skills.

Historically, researchers blamed aloof, cold, and emotionally detached parents for causing their children's autism. Specifically, the influence of Freudian theories led scientists to identify "refrigerator mothers," who were uncaring and refrained from physical affection, creating children with communication and social impairments (Schreibman, 2005). Individuals with ASD do experience difficulties with social and emotional reciprocity, which is important in forming secure attachments to others (Dissanayake \& Sigman, 2001). However, despite evidence to support this theory of a failure to develop attachments, recent research has demonstrated that children with ASD are capable of forming secure attachments to others. Dissanayake and Sigman (2001) compared the attachment styles between parents and typically 
developing children to parents and children with autism. They concluded that children with ASD were equally capable of forming secure attachments with their parents despite deficits in social reciprocity.

The socialization deficits in ASD are so significant that "even the highest functioning individuals show deviance that is readily apparent to laypersons" (Volkmar, 1987; pg. 47). This is easily observed among children and adolescents with AS who have high IQ scores. Children with AS are typically interested in interacting with their peers, but lack the necessary appropriate social skills to successfully build friendships. They often exhibit inflexible adherence to rules or rituals, egocentric behavior, and circumscribed interests. These difficulties can lead to bullying, peer rejection, and school non-attendance among children with AS, which have been shown to lead to social isolation in adulthood (Ghaziuddin \& Zafar, 2008). This is compounded by emotional difficulties such as episodic agitation and mood swings, which are common in individuals with AS (Tani et al., 2012). Despite these difficulties, individuals with AS have a better long-term prognosis than individuals with other forms of ASD and lower IQ.

Of note, individuals who engage in stereotypies exhibit less positive social skills than those without stereotypic behavior (Matson, Smiroldo, \& Bamburg, 1998). Engagement in repetitive behaviors inhibits social interaction and is thought to be one of the most isolating symptoms of ASD, because it hinders the development of close friendships. If children with ASD fail to develop typical social skills this can hinder their ability to live in the least restrictive setting possible in the future (Matson, Taras, Sevin, Love, \& Fridley, 1990). It has been demonstrated that most adults with autism lack identifiable friends and a social support system, often failing to be successfully employed, marry, or have children. Clinicians often target social skills as an area for treatment in children with ASD, because poor socialization can lead to 
further psychological distress. Considering that children with ASD exhibit a wide variety of social skills deficits and abnormalities, researchers have developed numerous tools to assess these skills.

\subsubsection{Assessment of social skills}

There are two primary approaches when assessing social behavior: standardized role-play tests and Likert-style rating scales (Matson \& Wilkins, 2009). Role-play tests were developed as a cost-effective alternative to naturalistic observation. Broadly, role-play tests consist of placing children in realistic situations where they can be assessed for whether or not they engage in operationally defined social behaviors. McFall and Marston (1970) published one of the earliest studies on social skills assessments. The researchers employed vignettes that created a scene where the confederate interacted with the subject, all of whom were shy males seeking assertiveness training, in a specific social context. The subject was rated on skills such as eye contact, tone of voice, and appropriateness of speech content. Based on the results of the roleplay test, the researchers developed specific treatment plans for each subject to address his social skills deficits.

The early role-play assessments lacked structure and only inter-rater reliability was assessed in terms of psychometrics (Matson \& Wilkins, 2009). As a result, an attempt was made to increase the psychometrics of these scales by standardizing the measures. The first standardized assessment for children was the Behavioral Assertiveness Test for Children (BAT$C$; Bornstein, Bellack, \& Hersen, 1977), which used discrete target behaviors that were rated based on the child's responses in standardized social situations. The BAT-C consisted of nine role-play situations, which were aimed at assessing appropriate assertiveness (e.g., one child promising to share a pair of scissors with the target child, but failing to do so). Bornstein and 
colleagues (1977) assessed speech volume, requests for other child to change behavior, and ratio of eye contact to duration of child's response. A modified version of the $B A T-C$ was utilized by Michelson, DiLorenzo, Calpin, and Ollendick (1982) to provide an overall rating of appropriate assertiveness based on 12 role-pay situations. The procedure was proven to be a reliable and valid measure of social behavior (Hobbs, Walle, \& Hammersly, 1984). Due to its success, other standardized role-play tests were developed including: Adolescent Play Inventory (API; Freedman, Rosenthal, Donahoe, Schlundt, \& McFall, 1979), Children's Interpersonal Behavior Test (CIBT; Van Hasselt, Hersen, \& Bellack, 1981), Conversation Probe (CONPROBE; Whitehall, Hersen, \& Bellack, 1980), Social Information Processing Interview (SIPI; Quiggle, Garber, Panak, \& Dodge, 1992), and Social Skills Test for Children (SST-C; Williamson, Moody, Granberry, Lethermon, \& Blouin, 1983).

Role-play tests have decreased in popularity and have been almost completely replaced by rating scales for assessing social skills in the child population. This is largely in part to increasing evidence that role-play scenarios do not always correspond with an individual's behavior in everyday life (Bellack, Hersen, \& Lamparski, 1979). These rating scales are penciland-paper assessments that have shorter administration times, no requirements for specific settings, and require little to no training for the examiners (Matson \& Wilkins, 2009). One of the most researched behavior rating scales is the Social Skills Rating System (SSRS; Gresham \& Elliot, 1990), which assesses social skills as well as academic performance and challenging behaviors. The scale is broken down into four subscales: cooperation (e.g., helping others, sharing, and complying with rules), assertion (e.g., initiating behaviors), empathy (e.g., showing concern for others and being respectful), and self-control (e.g., responding appropriately to conflicts). There are separate versions for Preschool (age 3-5), Elementary (grade kindergarten- 
6), and Secondary (grade 7-12) (McClelland \& Scalzo, 2006). One major criticism of the SSRS and other behavior rating scales is that they fail to provide information about possible antecedents and consequences of the problem behaviors (McClelland \& Scalzo, 2006). This can hinder a clinician's ability to develop an effective treatment plan.

The SSRS was revised to address some of these issues and re-released as the Social Skills Improvement System—Rating Scales (SSIS-RS; Gresham, Elliott, Cook, Vance, \& Kettler, 2010). The SSIS-RS consists of three separate forms (parent/caregiver, teacher, and child). The parent and child forms have two subscales: social skills and problem behaviors. The social skills subscale is further broken down into the following subdomains: communication, cooperation, assertion, responsibility, empathy, engagement, and self-control. The problem behaviors subscale is broken down into: externalizing, bullying, hyperactivity/inattention, internalizing, and autism spectrum. The teacher rating form contains an additional subscale to assess academic competence. Each item on the social skills and problem behaviors subscales is rated on a four point scale for frequency of the behavior.

The SSIS-RS has high reliability overall and for the individual subscales with estimates ranging from .77 to .92 (Gresham et al., 2010). In terms of convergent validity, the scale is moderately to highly correlated with other common social skills assessments. It has also been demonstrated to effectively differentiate between individuals with various disorders including ADHD, ASD, emotional/behavioral disturbance, and intellectual disability (Gresham et al., 2010). Cross-informant agreement for the SSIS-RS is weak to moderate: parent-teacher .30, child-teacher .21, and child-parent .21 (Gresham et al., 2010).

Although the SSIS-RS contains a subscale to assess features of ASD it was not designed specifically for that population. However, the Behavioral Assessment of Social Interactions in 
Young Children (BASYC; Callahan, Gillis, Romanczyk, \& Mattson, 2011), was specifically developed to measure social behavior in children with ASD. It is meant to serve as part of a comprehensive diagnostic evaluation and aid in developing effective interventions. The measure uses naturalistic, analog behavioral observation in a semi-structured setting. Each social skill item is presented as a behavioral task requiring social interaction. The measure takes 10 to 15 minutes to administer with the child and the examiner alone in a structured setting. The examiner presents the child with 20 different items in succession and records whether the child responds verbally, with a gesture, or not at all. There are three response indices for the measure: social initiation, social responsivity, and social interaction combined. The measure is consistent across different coders, with a high inter-rater reliability of .92 . The $B A S Y C$ was also found to be significantly correlated with other social skills measures with correlation scores ranging from .37 to .63 (Callahan et al., 2011).

The SSRS/SSIS-RS evaluates other behaviors aside from just social skills and the BASYC requires some direct observation. Whereas, the Matson Evaluation of Social Skills with Youngsters (MESSY; Matson, 1988) assesses appropriate and inappropriate social skills using parent/caregiver and teacher reports of frequency. The measure was initially developed in 1983 to assess social skills in the child population. The items that were included in the MESSY were the result of a comprehensive review of other standardized measures that had items to assess social behaviors. From this larger pool of items, two independent raters chose the items they believed to best fit the definition of social skills. The original version had 62 items on the selfreport form and 64 items on the teacher report form (Matson, Rotatori, \& Helsel, 1983). Since this time, the MESSY has been translated into nine languages other than English: Japanese (Matson \& Ollendick, 1988), Chinese (Chou, 1997), Dutch (Prins, 1997), Hindi (Sharma, 
Sigafoos, \& Carroll, 2000), Spanish (Mendez, Hildalgo, \& Ingles, 2002), Hebrew (PearlmanAvnion, \& Eviator, 2002), French (Verté, Roeyers, \& Buysse, 2003), Turkish (Bacanli \& Erdoğan, 2003), and Slovakian (Vasil'ová \& Baumğartner, 2004). The original version of the MESSY has been used to research social skills in various populations including children with intellectual disabilities (Matson \& Barrett, 1982), hearing and visual impairments (Matson, Heinze, Helsel, Kapperman, \& Rotatori, 1986; Matson, Macklin, \& Helsel, 1985; Raymond \& Matson, 1989), bipolar disorder (Goldstein, Miklowitz, \& Mullen, 2006), depression (Helsel \& Matson, 1984), ASD (Matson, Stabinsky-Compton, \& Sevin, 1991), and anxiety disorders (Strauss, Lease, Kazdin, Dulcan, \& Last, 1989).

The creation of a second edition of the MESSY, the MESSY-II (Matson, 2010), was the result of a need for updated psychometric properties on the original measure. The standardization of the MESSY-II used a new normative sample and has an updated factor structure. The MESSY-II also divides the scoring into age cohorts and provides cut-off scores. All 64 items on the MESSY-II refer to observable social behaviors as opposed to vague personality traits (e.g., "Helps a friend who is hurt." instead of "Is a caring person."). It also breaks apart the social skills into two broad categories: appropriate and inappropriate social behaviors. These considerations allow for easier administration and interpretation (Matson, 2010). By including separate norms for the three different age cohorts (i.e., 2-5, 6-9, and 10-16), the measure also effectively considers differences in social skills due to developmental level.

The MESSY-II can be used in a variety of settings with a broad range of children. There are separate norms for typically developing children and those diagnosed with ASD. The measure is highly effective at identifying deficiencies in social skills with the use of cut-off scores. The utility of these cut-off scores was tested with a sample of children with ASD. They 
were found to fall within the no/minimal impairment range on the inappropriate social skills factors (Matson et al., 2011). Conversely, children with ASD were found to fall within the severe impairment range for the appropriate social skills factor. This lends support to the idea that children with ASD demonstrate a significant deficit in appropriate social skills.

Based on which items were endorsed, a clinician can develop a behavioral modification plan or some other type of intervention. Once a child has begun receiving some form of intervention, the MESSY-II can be used to make an evaluation of the effectiveness of the treatment program. In the school system, the MESSY-II can be used to assess social skills as an area for inclusion in a child's Individualized Education Program (IEP).

\subsection{Intelligence Quotients}

\subsubsection{History of intelligence testing}

Francis Galton was the first man to focus on developing psychometric measures for studying individual differences (Goodwin, 2008). In 1869, Galton wrote Hereditary Genius, which used statistical evidence to demonstrate his belief that intelligence was an innate characteristic. Galton's ideas spread to the United States, and his cause was enthusiastically taken up by James McKeen Cattell, who coined the term 'mental test.' Cattell also introduced reaction time testing to American psychology laboratories (Goodwin, 2008). He performed statistical correlations to try and find relationships between physical measurements and students' performances in academic courses. Cattell did not find any significant correlations, and had to conclude that his mental tests were unrelated to academic performance (Wissler, 1965).

The first true intelligence test was developed in 1905 by Alfred Binet, a French psychologist employed by school officials in Paris to identify children who required special education (Goodwin, 2008). Binet added age levels to the 1908 revision of his tests. This 
allowed examiners to assign individuals a mental level that could be compared to their actual age. The French education system determined that children whose mental level was two years or more behind their age should be placed in special education classes and labeled as débiles, or "weak ones." Binet defined intelligence as "the faculty of adapting oneself. To judge well, to understand well, to reason well—-these are essential wellsprings of intelligence" (Fancher, 1985, p. 74). He was of the belief that intelligence could be increased with specific training. This was contrary to the eugenicist belief that intelligence was a fixed trait.

The intelligence test developed by Binet was introduced to the United States by Henry Goddard while he was working at the Vineland Training School for the Feeble-Minded (Goodwin, 2008). Goddard proposed new diagnostic categories: idiots (mental age one to two), imbeciles (mental age three to seven), and morons (mental age eight to twelve) (Goddard, 1910). Contrary to Binet, Goddard strongly believed that intelligence was an inherited trait and low intelligence could be linked to a single recessive gene (Goodwin, 2008). Goddard was an ardent eugenicist, who argued that individuals deemed as mentally deficient (i.e., mental age of 12 or below) should be prohibited from reproducing through sterilization. He believed that this process was necessary so the "bad gene" could be eradicated from the population (Goddard, 1912). He introduced his tests to Ellis Island, and mental testing became a main component of the screening process for immigrants to the United States in the early 1900s.

The first major revision of Binet's test was completed by Lewis Terman, a psychologist at Stanford University. He added some new subscales and then standardized the test using 2,300 participants before publishing what came to be known as the Stanford-Binet test in 1916 (Goodwin, 2008). Terman introduced the term intelligence quotient (IQ), which gave a numerical representation of the relationship between mental age and actual age. He was of the 
opinion that mental capacity could be represented by a single number. Terman wanted to use his concept of an IQ score to identify children at the upper end of the continuum who could be cultivated to reach their full potential. He established a study to identify the top $1 \%$ of California students and classify them as gifted. Once he established a sample, Terman compiled his findings in his book Genetic Studies of Genius: Mental and Physical Traits of a Thousand Gifted Children (Terman, 1925).

Intelligence testing was quickly popularized with the entrance of the United States into World War I. The Army recruited Robert Yerkes, a comparative psychologist from Harvard, to create mental tests that would identify soldiers with special skills, so they could be placed in officer training (Goodwin, 2008). Yerkes addressed the issue of illiteracy among recruits by developing two versions of his test. The Army Alpha test was given to those who were able to read and follow written instructions. Whereas, the Army Beta test was given to those with poor to no reading ability. Retrospectively, the Army did not benefit from the administration of these tests. However, the method was efficient for streamlining placement of new soldiers during wartime recruitment (Kevles, 1968). The Army project provided evidence that mental testing could be conducted on a large scale. Consequently, IQ tests were quickly introduced to educational and industry settings (Goodwin, 2008).

\subsubsection{Intelligence testing for children}

Intelligence testing for children has come a long way from the days of Binet's assessment to identify débiles. Psychologists today administer children IQ tests for a variety of reasons ranging from diagnosis of intellectual disability to placement in gifted programs. The most commonly administered tests are the Wechsler Intelligence Scale for Children-Fourth Edition (WISC-IV; Wechsler, 2003) and the Stanford-Binet Intelligence Scale-Fifth Edition (SB5; Roid, 
2003b). Accurate IQ testing is critical for diagnosing intellectual disability, because a subaverage IQ score is the primary diagnostic criterion in the DSM-IV-TR (APA, 2000)

\subsubsection{Assessment and diagnosis of ID}

The American Association on Mental Retardation (AAMR) defines Intellectual Disability (ID), as "a disability characterized by significant limitations both in intellectual functioning and in adaptive behavior involving conceptual, social, and practical adaptive skills" (Feldman, 2006). This dual-deficit approach to understanding ID was popularized by Heber (1959) and the AAMR, now called the American Association of Intellectual and Developmental Disabilities (AAIDD). The AAIDD has been influential in the development of diagnostic criteria by the American Psychiatric Association (APA) and the World Health Organization (WHO) (Greenspan, 1999).

In the 1992 revision of the AAMR manual, ID was defined as "substantial limitations in present functioning." The individual needed to demonstrate subaverage intellectual functioning combined with limitations in two or more of the following adaptive skill areas: communication, self-care, home living, social skills, community use, self-direction, health and safety, functional academics, leisure, and work. These deficits had to be apparent before the individual was 18 years of age. This definition was controversial for its inclusion of the phrase 'present functioning,' which implied that ID was a transient condition and the individual could be rehabilitated (Luckasson et al., 1992). The 1992 edition of the AAMR manual also raised the IQ cutoff between borderline and Mild ID from 70 to 75 to address the error that is inherent in all tests (Greenspan, 1999).

To address some of the difficulties clinicians faced when using the 1992 AAMR manual, the DSM-IV (APA, 1996) had a decidedly different definition of ID (Cuskelly, 2004). The DSM- 
$I V$ and the DSM-IV-TR, classified ID as an Axis II disorder (APA, 2000). In order for an individual to receive an Axis II diagnosis of ID their IQ must meet or fall below 70 (approximately two standard deviations below the mean). Intellectual disability is subdivided into four distinct categories of impairment: Mild, Moderate, Severe, and Profound. Individuals with Mild ID have an IQ score within the range of 50/55 to 70. Individuals with Moderate ID have an IQ score falling between the ranges of 35/40 to 50/55. Individuals with Severe ID have an IQ score falling within the range of $20 / 25$ to $35 / 40$. Finally, individuals with Profound ID have and IQ below 20/25 (Halgin \& Whitbourne, 2007).

Subaverage intellectual functioning is the first of three criteria that needs to be met for a diagnosis of ID. Second, the person must exhibit impairments in two or more of the following areas of adaptive functioning: communication, self-care, home living, social/interpersonal skills, work, leisure, health, and safety (APA, 2000). Adaptive functioning refers to the skills an individual needs to live independently in comparison to others of the same age. The final criterion is that the onset of impairments in intellectual and adaptive functioning must occur before the individual is 18 years of age (APA, 2000).

\subsubsection{Prevalence and etiology of ID}

As a result of the many different definitions of ID over the years, it can be difficult to ascertain an accurate estimate of the prevalence rate (Leonard \& Wen, 2002). Overall, there are higher rates of ID among children than adults, which could be linked to more awareness of diagnostic criteria among parents and doctors today then historically. There is also a higher rate of ID among males. Leonard and Wen (2002) conducted an extensive literature review and found that Severe ID occurs at a rate of approximately 3.8 in a thousand people, whereas Mild ID occurs at a rate of approximately 35 in a thousand people. 
Approximately $85 \%$ of individuals with ID fall within the Mild range and can typically live with minimal outside support as adults. Another 10\% of individuals with ID fall in the Moderate range. Individuals in this group require more supervision and assistance in some activities of daily living. Individuals with Severe ID make up 3\% to $4 \%$ of all individuals with ID. These individuals require assistance from their families or a community support service for most activities of daily living and may struggle to find suitable employment. People with Profound ID account for the last $1 \%$ to $2 \%$ of individuals with ID, and require constant support and supervision. Those with Profound ID are the most impaired of all individuals with ID.

While there is no single cause for ID, many predisposing factors have been identified. These include mental disorders, birth complications, medical conditions during infancy or childhood, genetics, embryonic mutations, and environmental deprivation (Shevell, 2008). Birth complications include, but are not limited to prematurity, inadequate nutrition during pregnancy, and anoxia. ID can also result from infections, injuries, or exposure to toxins during infancy or childhood. Some genetic conditions leading to ID involve recessive genes (e.g., Tay-Sachs disease) or chromosomal abnormalities (e.g., Down syndrome) (Cans, Wilhelm, Baille, du Mazaubrun, Grandjean, \& Rumeau-Rouquette, 1999). Embryonic mutations may be due to maternal infections or prenatal toxins (e.g., Fetal Alcohol Syndrome). Common forms of environmental deprivation that have been noted as predisposing factors include a lack of social contact and other forms of environmental stimulation (Cans et al., 1999).

\subsubsection{IQ and social skills}

There is a dearth of research on the relationship between intellectual functioning and the presence of appropriate or inappropriate social skills in the general population. The research that does exist indicates that there is a correlation between lower IQ and poorer social skills 
(McClelland et al., 2000). There is more research on the relationship between IQ and social skills in children with ASD. Schatz and Hamdan-Allen (1995) demonstrated that children with HFA have significantly greater impairments in socialization than typically developing children with similar intelligence. In general, social skills are more severely impaired in ASD than would be predicted by intellectual functioning level (Freeman, Del'Homme, Guthrie, \& Zhang, 1999; Klin, Saulnier, Sparrow, Cicchetti, Volkmar, \& Lord, 2007). Of note, individuals with AS often have higher IQ scores than individuals with other PDD diagnoses. Researchers have found that those with AS demonstrate fewer deficits in social skills, although the socialization domain is identical in the diagnosis of AS and other PDDs. One explanation for this discrepancy is that the nature of the deficits in AS are distinctly different from individuals with other PDDs (Klin, Sparrow, Volkmar, Cicchettim \& Rourke, 1995). Thus, even among individuals with ASD, IQ is a predictor of social skills.

\subsection{Purpose}

Children with ASD experience clear deficits in socialization regardless of their intellectual and adaptive functioning levels (Carpenter et al., 2002). Despite the common occurrence of intelligence testing and measures of social skills among children with ASD, there is limited research on the relationship between IQ and social skills, and how children with ASD differ from children without ASD. To date, there have been numerous publications examining the reliability and validity of the MESSY-II for both typically developing children and children with ASD (Matson et al., 2010; Matson et al., 2011; Matson et al., 1991), but nothing linking the measure with IQ scores to examine the combined effects. Therefore, the main purpose of the current study was to increase the literature on how intellectual functioning differentially impacts 
the social skills of children with ASD versus children without ASD. Of particular interest was the impact of ASD diagnosis among children with average or above average IQ scores.

The current study had three main goals to aid in fulfilling this purpose. The first goal of the current study was to replicate findings in the literature that higher IQ is associated with greater appropriate social skills and fewer inappropriate social skills. Second, this study aimed to replicate findings that the presence of ASD is associated with fewer appropriate social skills. Finally, the current study aimed to address the question of whether or not there is an interaction between IQ and presence of ASD when assessing both inappropriate and appropriate social skills. Identifying this interaction has important implications for research on children with ASD. Researchers often overlook IQ as a contributing factor and place more focus on verbal communication skills. Non-verbal intelligence is important to consider for individuals with ASD who have impaired communication and could help drive treatment for these more severely impaired individuals. The results are also of significance to clinicians involved in social skills training for children with ASD across all levels of intellectual functioning.

Based on the existing literature on socialization in relation to autism and IQ separately, several predictions were made regarding the outcome of this study. First, it was hypothesized that there would be a significant main effect of IQ score on the social skills measure. Adaptive social skills would be higher for children with higher IQ, while hostile/inappropriate social skills would be higher for children with lower IQ. Additionally, there would be a significant difference between the ASD and non ASD groups on the social skills measure. Adaptive social skills would be higher for non ASD children and lower for children with ASD. Finally, it was predicted that there would be an interaction between IQ and ASD diagnosis. Children with high 
IQ and ASD would have less adaptive social skills than children with high IQ without ASD, while there would be less discrepancy by diagnosis among the low IQ participants. 


\section{CHAPTER 2. METHOD}

\subsection{Participants}

Participation in the current study was based on participation in a larger research study for which data were collected over a period of multiple years. Collection of data for other research is still taking place at the present time. Participants for this study were children who received a developmental disability, gifted, or psychoeducational assessment at an outpatient clinic affiliated with a university in the southeastern United States. Participants were assigned to one of two groups: ASD or non ASD. Assignment to the ASD group was based on DSM-IV-TR and ICD-10 diagnostic criteria. Two raters were required to be in agreement on diagnostic criteria in order for a classification of ASD to be made. The ASD group consisted of participants with Autistic Disorder or PDD-NOS. The initial sample consisted of 657 children, but only 137 had known IQ scores. Of the 137 with recorded IQ scores, only 130 had corresponding MESSY-II scores. Another 11 participants were excluded because they were given alternative intelligence measures (e.g., adaptive functioning score or unknown measure). There were 119 participants in the study who met all the inclusion criteria, with $65.5 \%$ male and $34.5 \%$ female. Participants ranged in age from 3 to 20 years old $(M=8.71)$. Furthermore, 16.4\% were African-American, 79.3\% were Caucasian, $1.7 \%$ were Hispanic, and $2.6 \%$ identified as 'other'.

\subsection{Measures}

DSM-IV-TR/ICD-10 Checklist. The DSM-IV-TR/ICD-10 Checklist (Matson, Gonzales, Wilkins, \& Rivet, 2008) was used as the main measure to decide whether children were placed in the ASD group or the non ASD group. The checklist includes criteria from the three core areas of autism (impaired socialization, impaired communication, and restricted repetitive and stereotyped patterns of behavior) as defined in the DSM-IV-TR (APA, 2000). Some of the 
socialization items include: "failure to develop social interactions," "lack of social/emotional reciprocity," and "marked impairment in nonverbal behaviors such as eye-to-eye gaze." Items to address impairment in communication include: "repetitive or idiosyncratic language," "impairment in the ability to initiate or sustain conversation with others," and "delay in the development of spoken language.” Finally, items to address the restricted and stereotyped patterns of behavior include: "a preoccupation with one or more stereotyped or restricted patterns of interests," "persistent preoccupation with parts of objects," and "stereotyped and repetitive motor movements." To broaden the scope of the checklist, some criteria that were included in the $I C D-10$ (WHO, 1992), but not found in the $D S M-I V-T R$, were also included: "lack of emotional response to other verbal or nonverbal communication," "impaired use of gestures to aid spoken communication," "lack of variation in speech," "specific attachments to unusual objects," "rarely seeking or using others for comfort in times of stress or comforting others when they are stressed," and "distress over changes in small, nonfunctional details in the environment." The checklist also includes an item that addresses whether the noted symptoms were observed before the child was 3 years old. In order for a child to meet criteria for ASD, there must be at least two endorsements for socialization deficits and one endorsement for either communication impairment or repetitive, restricted or stereotyped patterns of behavior on the checklist. The DSM-IV/ICD-10 Checklist has excellent reliability, ranging from $\mathrm{r}=.89$ to $\mathrm{r}=.96$ (Matson et al., 2008).

Wechsler Intelligence Scale for Children-Fourth Edition (WISC-IV). The most recent version of the WISC, which originated at the Wechsler Bellevue Form II in 1946, was produced in 2003 after having been renormed using a sample of 2,200 children in the United States aged 6 years 0 months to 16 years 11 months (Wechsler, 2003). The split-half method was used to 
assess the internal consistency of the measure, and it was found to be .98 for the full scale IQ. The measure is also stable across time, with high test-retest reliability (WISC-IV Technical Manual \#2, 2003). The measure produces scaled scores for 11 different age cohorts. In the current study, the WISC-IV was administered by doctoral level clinical psychology graduate students working under the supervision of a licensed clinical psychologist. The pencil-and-paper test takes between 60 and 90 minutes to administer depending on age and intellectual functioning level. The WISC-IV produces a full scale IQ (FSIQ), which is the composite score for the entire scale. It also produces four index scores: verbal comprehension, perceptual reasoning, working memory, and processing speed. Only the FSIQ was considered for this study.

Stanford-Binet Intelligence Scales- $5^{\text {th }}$ Edition (SB5). The most recent version of the Stanford-Binet, which can trace its origins back to the first intelligence tests developed by Alfred Binet in France at the turn of the $20^{\text {th }}$ century, is the SB5 (Roid, 2003b). A standardization sample of 4,800 people aged 2 to 96 years was utilized to develop norms for the SB5. The test has an internal-consistency reliability score of .98 for the FSIQ (Roid, 2003a). Test-retest reliability scores ranged from .93 to .95 (Roid, 2003a). Each subtest, of which there are 10 in the standard administration, takes about five minutes to administer. The five verbal subtests are combined to formulate the Verbal IQ (VIQ), and the five nonverbal subtests are combined to formulate the Nonverbal IQ (NVIQ). In the current study, the SB5 was administered by doctoral level clinical psychology graduate students working under the supervision of a licensed clinical psychologist. Some individuals were only administered the abbreviated version of the measure. This includes two routing subtests, one verbal-based test, and one non-verbal based test. It produces an abbreviated battery IQ (ABIQ). There is a high correlation between scores on the 
ABIQ and the FSIQ, $r=.71, p<.001$ (Newton, McIntosh, Dixon, Williams, \& Youman, 2008).

Depending on which was obtained, the FSIQ or ABIQ was considered in this research.

Wechsler Preschool and Primary Scale of Intelligence- Third Edition (WPPSI-III). The most recent version of the scale, the WPPSI-III (Wechsler, 2002) is designed to be administered to children ages 2 years and 6 months to 7 years and 3 months. The measure was normed on a sample of 1,700 children. It was found to have a reliability of .89 to .96 on the composite scales (The Psychological Corporation, 2002). The WPPSI-III has a test-retest reliability of $r=.92$ and inter-scorer agreements ranging from .98 to .99 (The Psychological Corporation, 2002). The WPPSI-III contains 14 subtests and can take from 30 to 60 minutes depending on the age and functioning level of the child. In the current study, the WPPSI-III was administered by doctoral level clinical psychology graduate students working under the supervision of a licensed psychologist. The assessments produced a VIQ, Performance IQ (PIQ), and FSIQ. Only the FSIQ was considered in this study.

Matson Evaluation of Social Skills for Youngsters-II (MESSY-II). The MESSY-II is a behavioral observation rating scale to assess appropriate and inappropriate social skills in children. Each of the 64 items loads onto one of three factors: Adaptive/Appropriate, Hostile, or Inappropriately Assertive/Overconfident (Matson et al., 2011). In this study, the measure was administered by doctoral level graduate students who had been trained by the author of the MESSY-II prior to administration. In general though, the MESSY-II can be administered by a school psychologist, clinical psychologist, school social worker, or researcher working under the supervision of a clinical or school psychologist. The examiner reads the instructions and then has the informant read each individual item and select the appropriate response. The informants are typically the parent and/or guardian of the child. They are asked to rate each item based on 
how often the child demonstrates each behavior $(1=$ not at all, $2=$ a little, $3=$ some, $4=$ much of the time, $5=$ very much). The scale requires between 10 and 25 minutes to administer fully, with the discrepancy based on how quickly or slowly the informant reads each item. The MESSY-II can be scored by hand in 5 to 10 minutes. The examiner transfers the raw score to the scoring protocol to determine the level of social functioning or dysfunctioning for that factor. For items where data is missing, the score for the missing item is determined by taking the average score for all the completed items in that factor.

The internal consistency of the MESSY-II was evaluated using a sample of 885 typically developing children ranging in age from 2 to 16 years and dividing the sample into three age cohorts: 2 to 5 years, 6 to 9 years, and 10 to16 years (Matson, Neal et al., 2010). The older cohorts had greater alpha values than the younger cohorts, with values ranging from .84 to .93 . This discrepancy suggests that older children have more consistent social skills than their younger counterparts (Matson, Neal et al., 2010). The split-half reliability of the measure was evaluated using a sample of 114 children with ASD and separating out the positive items from the negative items (Matson, Horovitz et al., 2010). The researchers found excellent split-half reliability of .90 for adaptive/appropriate items and .93 for hostile and inappropriately assertive/overconfident items. The inter-rater reliability of the scale was calculated using a sample of 33 children with ASD (Matson, Horovitz et al., 2010). The researchers found moderate inter-rater reliability for the total score, $r=.51, p<.001$, and high inter-rater reliability for both the positive, $r=.71, p<.001$, and negative items, $r=.73, p<.001$.

The convergent and divergent validity of the MESSY-II was evaluated using the same age cohorts as the reliability analysis (Matson, Neal et al., 2010). To evaluate convergent validity, the researchers utilized the adaptive subscale of the Behavior Assessment Scale for Children- 
Second Edition (BASC-II; Reynolds \& Kamphaus, 2006). Then they utilized the total score on the Autism Spectrum Disorder-Comorbidity for Children (ASD-CC; Matson \& Wilkins, 2008) to evaluate divergent validity with the subscales and total score on the MESSY-II. Both convergent and divergent validity scores ranged from good to strong. However there was a noted weakness of the MESSY-II for measuring social skills in younger children (i.e., the 2 to 5 years old age cohort). This is likely explained by the high degree of variability in social skills at that stage in development.

The factor structure of the measure was evaluated using an exploratory factor analysis that yielded a three-factor structure (Matson et al., 2011). Two factors were found to relate to inappropriate social skills (i.e. hostile and inappropriately assertive/overconfident) and one factor was found to relate to appropriate social skills (i.e. adaptive/appropriate). The three factors accounted for $32.06 \%$ of the total variance with factor 1 (hostile) accounting for $17.54 \%$, factor 2 (adaptive/appropriate) accounting for $8.80 \%$, and factor 3 (inappropriately assertive/overconfident) accounting for $5.30 \%$ of the variance.

The renorming of the MESSY included the addition of cut-off scores for each of the three factors (Matson et al., 2011). The cut-offs were established using the definition of clinical significance as two standard deviations or more from the mean (Jacobson \& Truax, 1991). The mean and standard deviation of the MESSY-II factors were calculated for each age cohort to compute separate cut-off scores.

\subsection{Procedure}

The IQ tests were administered to the participants by doctoral level graduate students working under the supervision of a licensed clinical psychologist. The tests were administered in a standardized fashion in accordance with the protocols from the test publishers. The MESSY-II 
was completed using the primary caregiver for the child as the informant. Directions were clearly printed on the measure and the parents were given the opportunity to discuss any questions or issues that arose as they were completing the measure. All measures were scored by trained graduate students and then recorded in the database. Throughout the course of data collection, supervision was provided by a licensed clinical psychologist. Approval was granted for the study by the Louisiana State University Institutional Review Board.

Specific criteria needed to be met for inclusion in this study. All participants must have been administered a valid IQ test and completed the MESSY-II to be considered for inclusion. For people who were missing data on the MESSY-II the ratings for missing items were calculated based on the procedure outlined in the test manual. This involved finding the factor to which the missing item belonged, computing the average raw score of all completed items on that factor, and substituting the average raw score for each missing item on the factor. Further, those in the ASD group must have met a cut-off score on the DSM-IV/ICD-10 Checklist. There were no outliers in the data. 


\section{CHAPTER 3. RESULTS}

To ensure that there were no significant differences between the two groups (ASD and non ASD) on demographic characteristics, the groups were compared on age, gender, and race. A chi-square analysis was completed for gender and race because these are categorical variables. There were no significant differences between groups on gender, $\chi^{2}(1, N=119)=1.063, p$ $=.161$, or race, $\chi^{2}(3, N=119)=6.628, p=.085$. A one-way analysis of variance (ANOVA) was completed for age and there was not a significant difference between the two groups, $F(1,105)$ $=.696, p=.764$. A separate ANOVA was conducted to see if IQ score varied significantly with age and the results were non-significant, $F(1,105)=.718, p=.741$.

\section{Table 1}

Demographic Characteristics by Diagnostic Group $(N=119)$

\begin{tabular}{|l|l|l|}
\hline Demographic Characteristics & $\begin{array}{l}\text { ASD } \\
(\mathrm{n}=42)\end{array}$ & $\begin{array}{l}\text { Non-ASD } \\
(\mathrm{n}=77)\end{array}$ \\
\hline Age (in years) & & \\
\hline Mean (SD) & $7.98(3.04)$ & $9.12(3.39)$ \\
\hline Range & $3-14$ & $3-20$ \\
\hline Gender, \% & & \\
\hline Male & $73.8 \%$ & $61.0 \%$ \\
\hline Female & $26.2 \%$ & $39.0 \%$ \\
\hline Race/Ethnicity, \% & & \\
\hline Caucasian & $69.0 \%$ & $85.1 \%$ \\
\hline African-American & $23.8 \%$ & $12.2 \%$ \\
\hline Hispanic & $4.8 \%$ & $0 \%$ \\
\hline 'Other' & $2.4 \%$ & $2.7 \%$ \\
\hline
\end{tabular}

Second, three main research questions were addressed with two separate multiple regressions: (1) Does IQ score have a significant effect on social skills? (2) Does a diagnosis of ASD have a significant effect on social skills? and (3) Is there an interaction between presence of ASD and IQ score in terms of social skills? ASD was conceptualized as a dichotomous variable with two groups. However, the wide range of IQ scores did not allow for equal sized cells, so 
the IQ variable was conceptualized as continuous. To center the variables for group membership, ASD was coded as +1 and non ASD was coded as -1 .

For the first set of analyses, IQ score and ASD/non ASD served as the predictor variables and adaptive/appropriate social skills served as the criterion variable. The adaptive/appropriate social skills score for each participant was computed by summing all the items for that factor on the MESSY-II. Correlation and multiple regression analyses were conducted to examine the relationship between adaptive/appropriate social skills and the three predictors. Table 2 summarizes the descriptive statistics and correlations. ASD/nonASD was negatively and significantly correlated with adaptive/appropriate social skills, indicating that children with ASD tended to have lower scores on the measure of adaptive/appropriate social skills. IQ scores were positively and significantly correlated with adaptive/appropriate social skills, indicating that children with higher IQ scores tended to have higher scores on the measure of adaptive/appropriate social skills. The multiple regression model for adaptive/appropriate social skills with both predictors was significant, $R^{2}=.373, F(2,106)=31.492, p<.001$. Upon inspection of the beta values, ASD diagnosis significantly predicted adaptive/appropriate social skills, $\beta=-.594, t(106)=-7.279, p<.001$. See Table 3 for a depiction of the beta values, standard errors, and standardized beta values for the predictor variables.

Table 2

Summary statistics and correlations for Adaptive/Appropriate Social Skills

\begin{tabular}{|c|c|c|c|}
\hline & Mean & SD & Correlation with Appropriate SS \\
\hline Adaptive SS & 64.80 & 16.98 & 1.000 \\
\hline ASD Diagnosis & -.34 & .94 & $-.609^{*}$ \\
\hline IQ Score & 93.54 & 18.48 & $.243^{* *}$ \\
\hline
\end{tabular}

Note: $*$ indicates $p<.001$ and $* *$ indicates $p<.05$ 
Table 3

Results of the regression analysis for Adaptive/Appropriate Social Skills

\begin{tabular}{|c|c|c|c|c|c|}
\hline & B & SE B & $\beta$ & $t$ & Sig. \\
\hline ASD Diagnosis & -10.674 & 1.466 & -.594 & -7.279 & .000 \\
\hline IQ Score & .042 & .075 & .045 & .553 & .581 \\
\hline
\end{tabular}

In the second linear multiple regression, IQ score and ASD/non ASD again served as the predictor variables and hostile/inappropriate social skills served as the criterion variable. The hostile/inappropriate social skills score for each participant was computed by summing all the items for the hostile and inappropriately assertive/overconfident factors on the MESSY-II. Correlation and multiple regression analyses were conducted to examine the relationship between hostile/inappropriate social skills and the three predictors. Table 4 summarizes the descriptive statistics and correlations. ASD/nonASD was positively and significantly correlated with hostile/inappropriate social skills, indicating that children with ASD tended to have higher scores on the measure of hostile/inappropriate social skills. IQ scores were negatively correlated with hostile/inappropriate social skills but non-significant. The multiple regression model for hostile/inappropriate social skills with both predictors was significant, $R^{2}=.238, F(2,106)=$ $3.176, p=.046$. Upon inspection of the beta values, ASD diagnosis significantly predicted hostile/inappropriate social skills, $\beta=.251, t(106)=2.512, p=.014$. See Table 5 for a depiction of the beta values, standard errors, and standardized beta values for the predictors.

\section{Table 4}

Summary statistics and correlations for Hostile/Inappropriate Social Skills

\begin{tabular}{|c|c|c|c|}
\hline & Mean & SD & Correlation with Hostile/Inappropriate SS \\
\hline Inappropriate SS & 74.61 & 24.49 & 1.000 \\
\hline ASD Diagnosis & -.34 & .94 & $.230^{*}$ \\
\hline IQ Score & 93.54 & 18.48 & -.019 \\
\hline
\end{tabular}

Note: $*$ indicates $p<.05$ 
Table 5

Results of the regression analysis for Hostile/Inappropriate Social Skills

\begin{tabular}{|c|c|c|c|c|c|}
\hline & B & SE B & $\beta$ & $\mathrm{t}$ & Sig. \\
\hline ASD Diagnosis & 6.515 & 2.593 & .251 & 2.512 & .014 \\
\hline IQ Score & .086 & .133 & .065 & .646 & .519 \\
\hline
\end{tabular}




\section{CHAPTER 4. DISCUSSION}

Currently, there is a paucity of empirical research published on the relationship between IQ, ASD, and social skills in children. Numerous studies have been conducted on social skills in children with ASD (Dawson \& Adams, 1984; Kanner, 1943; Volkmar et al., 1997; White et al., 2007), but they often fail to take into account level of intellectual functioning. In all instances

(i.e., typical development, ID, and ASD), it is important that assessments of social skills address both appropriate social skills and inappropriate social skills. Understanding the patterns of social behavior in children, especially children with clear deficits in appropriate social skills, can help inform clinicians during treatment planning. This goal enhances the suitability of interventions used based on the diagnoses and functioning level of each individual child.

Thus, the aim of this study was to investigate patterns of social skills in both children with and without ASD at various IQ levels. ASD diagnosis significantly contributed to both regression models. It significantly predicts both adaptive/appropriate and hostile/inappropriate social skills. There were also significant correlations between factors. A diagnosis of ASD was significantly correlated with both adaptive/appropriate social skills and hostile/inappropriate social skills. Children with ASD had higher ratings on the hostile/inappropriate social skills items and lower ratings on the adaptive/appropriate social skills items than children without ASD. Secondly, IQ scores were significantly correlated with adaptive/appropriate social skills. Children with higher IQ scores had higher ratings on adaptive/appropriate social skills items than children with lower IQ scores. These initial findings are in accordance with previous research and support the use of the MESSY-II for measuring social skills in children of varying functioning levels. 
The hypothesis that there would be a main effect of ASD diagnosis on social skills was confirmed by the current study. Children with ASD had lower ratings on the measure of adaptive/appropriate social skills and higher ratings on the measure of hostile/inappropriate social skills. These findings are in agreement with previous research on social skills performance in children with ASD (Dawson \& Adams, 1984; Kanner, 1943; Volkmar et al., 1997; White et al., 2007). Children with ASD experience clear deficits in appropriate social skills leading to isolation from peers and poorer overall psychological functioning.

The hypothesized interaction between IQ and ASD diagnosis on ratings of social skills had not been directly evaluated in previous research. No interaction was observed in the current analyses. This is somewhat unexpected given that previous research had indicated a clear social deficit in individuals with ASD that would not be predicted by their intellectual functioning level (Freeman et al., 1999; Klin et al., 2007; Schatz \& Hamdan-Allen, 1995). It was predicted that there would be a clear difference between children with and without ASD who had average or above average IQ scores. Of note, children with AS or HFA typically have higher nonverbal IQ scores than verbal IQ scores, and demonstrate clear deficits on tasks requiring representations and symbolizations (Yirmiya \& Sigman, 1991). These children are characterized by a severe impairment in socialization, which is not seen in peers with similar cognitive functioning levels. Limitations of the current study may have contributed to the failure to find an interaction. The current sample did not include many children with above average IQ scores, with only 13 participants $(\mathrm{ASD}=2$; non $\mathrm{ASD}=11$ ) with an IQ greater than 110 . With a larger sample it is possible that a greater difference in social skills would have been observed between children with autism who are higher functioning and their non ASD peers. Future research on this topic may benefit from focusing exclusively on children with average or above average IQ scores. 
Another possible explanation for the failure to find an interaction between IQ and ASD is that RRBIs, a core feature of ASD, have been shown to significantly decrease social skills. The type and intensity of RRBIs vary with IQ and ASD severity. Researchers have previously categorized RRBIs into two main types: "lower order" sensory motor behaviors (e.g., rocking, spinning, hand-flapping, and unusual sensory interests) and "higher order" behaviors (e.g., resistance to change, compulsions, and rituals) (Cuccaro et al., 2003). The lower order behaviors are more common in individuals of lower IQ and often seen in individuals with ID. They are highly prohibitive to the development of adaptive social skills. Conversely, the higher order behaviors are more common in individuals with higher IQ. These higher order behaviors do not have a significant impact on overall adaptive functioning (Szatmari et al., 2006).

Relying on parent report alone may affect rating accuracy. In this instance, parents were only reporting on their observations of their children in the home setting. As a result, they may have been unable to accurately comment on how their children interact with peers at school or during other activities. The parents may also have been biased in their ratings in an attempt to secure particular diagnoses for their children or for other reasons. Future research on this topic may benefit from the inclusion of teacher reports or child reports when appropriate.

Another possible limitation was the composition of the non ASD group. Other factors aside from ASD have been shown to negatively impact social skills in children independent of IQ. Some of the children in the non ASD group had Axis I diagnoses. These other disorders have been found to negatively impact social skills. They include depression (Kovacs \& Goldston, 1991), ADHD (de Boo \& Prins, 2007), and social phobia (Spence, Donovan, \& Brechman-Toussaint, 1999). The sample also included children with disruptive behavior problems who were not diagnosed with ASD or ID. Overall, 50 of the 77 children in the non 
ASD group demonstrated either atypical development or psychopathology. With a larger sample, it may have been possible to use more rigorous exclusion criteria. Future research should focus on a comparison of children with ASD to typically developing children without any noted forms of psychopathology. The sample may also have been problematic in terms of the age range of the children. Researchers have demonstrated that the MESSY-II is not as accurate at measuring social skills in children ages 2 to 5 years old as compared to older children (Matson, Neal et al., 2010). The current sample had 18 children in the 2-5 age range. Future research should focus on older children. This conclusion is based on the fact that older children exhibit more independence in activities of daily living and more advanced communication skills leading to more reliable ratings on the adaptive/appropriate social skills scale.

The findings of this research have important implications for assessment and treatment of social skills deficits in children. Throughout the lifespan, level of social skills is an important predictor of overall psychological well-being (Segrin \& Taylor, 2007). In children, poor social skills lead to peer-rejection, which can in turn lead to overt aggression or other disruptive behaviors (Dodge, 1983). Researchers have demonstrated that intervening early when deficits in socialization are first identified can lead to increased social validity and overall functioning (McClelland \& Scalzo, 2006). Implementing behavior modification plans in early childhood can increase social skills in individuals with intellectual disability and/or an ASD diagnosis.

Before a clinician can begin treatment, accurate assessment of social skills is necessary for developing effective behavioral interventions. Results of this study support the necessity of assessing social skills in children presenting with learning difficulties or emotional disturbances, especially those with a suspected or known ASD diagnosis. Children with ASD have significantly lower rates of appropriate/adaptive social skills than their non ASD peers. Thus, 
treatment for children with ASD of all IQ levels should focus on improving social functioning.

For those individuals with higher IQ, clinicians should be aware that their cognitive abilities may serve as a buffer against peer rejection (Newcomb, Bukowski, and Pattee, 1993). The results of the current study support this notion. Individuals with higher IQ had more appropriate social skills than children of the same age with lower IQ scores. One important exception to this finding was that children with higher IQ and ASD had decreased social skills compared to children of the same cognitive functioning level without ASD. Clinicians working with children and adolescents with ASD who are higher functioning should focus on teaching skills necessary for appropriate social interaction. These children may especially benefit from social skills groups with their peers (Williams, 1989). Overall, children with ASD who have higher IQ scores have a better prognosis (Ben-Itzchak \& Zachor, 2007) and benefit from different interventions than those with lower IQ scores.

In sum, more controlled research is needed to clarify the relationship between ASD, intellectual functioning, and social skills. The current research lends support to the emphasis placed on increasing social skills in individuals with ASD. Individuals with ASD of all levels of intellectual functioning can benefit from interventions focused on teaching adaptive and appropriate social skills to aid in interactions with peers and adults (e.g., applied behavior analysis, parent training, peer training, video modeling, and social skills groups) (Reichow \& Volkmar, 2010). More information is needed regarding comorbid psychiatric disorders that compound the social skills deficits inherent to individuals with ASD, and how they negatively affect social skills in typically developing children. Future research on this topic should include comorbid diagnoses and how they interact with ASD as additional predictor variables. Accurate information on psychiatric diagnoses and intellectual functioning allows the clinician to make the 
most informed decisions about appropriate interventions and predict long-term prognoses. Recently, empirical research on the effectiveness of behavioral interventions has led individual states to require that private insurance companies provide coverage for some autism-related services (Bouder, Spielman, \& Mandell, 2009; Krauss, Gulley, Sciegaj, \& Wells, 2003). Thus, replications and extensions of this study may provide the empirical support for social skills training for children with ASD that is necessary for policy and lawmakers when they are deciding which interventions should be included in public schools or covered by medical insurance. Impairments in social skills in childhood generally compound throughout the lifespan. If they go untreated, high levels of hostile/inappropriate social skills may hinder an individual's placement in the least restrictive possible environment and be prohibitive to community integration (Matson et al., 1990). 


\section{REFERENCES}

Angst, J. (2009). Psychiatry NOS (not otherwise specified). Salud Mental, 32, 1-2.

American Psychological Association. (1952). Diagnostic and statistical manual of mental disorders. Washington DC: American Psychiatric Association.

American Psychological Association. (1980). Diagnostic and Statistical Manual of Mental Disorders. Washington DC: American Psychiatric Association.

American Psychological Association. (1987). Diagnostic and Statistical Manual of Mental Disorders (3rd, revised Ed.). Washington DC: American Psychiatric Association.

American Psychological Association. (1994). Diagnostic and Statistical Manual of Mental Disorders (4th Ed.). Washington DC: American Psychiatric Association.

American Psychological Association. (2000). Diagnostic and statistical manual of mental disorders (4th ed., text rev. Ed.). Washington, DC: American Psychiatric Association.

American Psychological Association. (2010, January 26, 2011). Proposed Revisions: Autism Spectrum Disorder Retrieved August 18, 2011, from http://www.dsm5.org/ProposedRevisions/Pages/proposedrevision.aspx?rid=94

Asperger, H. (1944). Autistic psychopathy in childhood. In U. Frith (Ed.), Autism and Asperger's syndrome (pp. 37-92). Cambridge: Cambridge University Press.

Bacanli, H., \& Erdoğan, F. (2003). Adaptation of the Matson Evaluation of Social Skills with Youngsters (MESSY) to Turkish. Education Sciences: Theory and Practice, 3, 368-379.

Bartlett, S. C., Armstrong, E., \& Roberts, J. (2005). Linguistic resources of individuals with Asperger syndrome. Clinical Linguistics and Phonetics, 19(3), 203-213.

Bellack, A.S., Hersen, M., \& Lamparski, D. (1979). Role play tests for assessing social skills. Are they valid? Are they useful? Journal of Consulting and Clinical Psychology, 47, 335342.

Ben-Itzchak, E., \& Zachor, D. A. (2007). The effects of intellectual functioning and autism severity on outcome of early behavioral intervention for children with autism. Research in Developmental Disabilities, 28, 287-303.

Bierman, K.L., Smoot, D.L., \& Aumiller, K. (1993). Characteristics of aggressive-rejected, aggressive (non-rejected) and rejected (nonaggressive) boys. Child Development, 64, 139-151.

Bleuler, E. (1913). Autistic thinking. American Journal of Insanity, 69(5), 873-886. 
Bornstein, M. R., Bellack, A. S., \& Hersen, M. (1977). Social skills training for unassertive children: A multiple baseline analysis. Journal of Applied Behavior Analysis, 10, $183-$ 195.

Bouder, J. N., Spielman, S., Mandell, D. S. (2009). Brief report: Quantifying the impact of autism coverage on private insurance premiums. Journal of Autism and Developmental Disabilities, 39, 953-967.

Callahan, E. H., Gillis, J. M., Romanczyk, R. G., \& Mattson, R. E. (2011). The Behavioral Assessment of Social Interactions in Young Children: An examination of convergent and incremental validity. Research in Autism Spectrum Disorders, 5, 768-774.

Cans, C., Wilhelm, L., Baille, M. F., du Mazaubrun, C., Grandjean, H., \& Rumeau-Rouquette, C. (1999). Aetiological findings and associated factors in children with severe mental retardation. Developmental Medicine \& Child Neurology, 41(4), 233-239.

Carpenter, M., Nagell, K., Tomasello, M., Butterworth, G., \& Moore, C. (1998). Social cognition, joint attention, and communicative competence from 9 to 15 months of age. Monographs of the Society for Research in Child Development, 63, 1-174.

Carpenter, M., Pennington, B. F., \& Rogers, S. J. (2002). Interrelations among social-cognitive skills in young children with Autism. Journal of Autism and Developmental Disorders, 32, 91-106.

Chou, K. (1997). The Matson Evaluation of Social Skills with Youngsters: Reliability and validity of a Chinese translation. Personality and Individual Differences, 22, 123-125.

Coie, J., Dodge, K., \& Kupersmidt, J. (1990). Peer group behavior and social status. In S. Asher \& J. Coie (Eds.), Peer rejection in childhood (pp. 17-59). Cambridge, UK: Cambridge Univ. Press.

Cooper, D. H., \& Farran, D. C. (1988). Behavioral risk factors in kindergarten. Early Childhood Research Quarterly, 3, 1-19.

Cuccaro, M.L., Shao, Y., Grubber, J., Slifer, M., Wolpert, C.M., Donnelly, S.L....Pericak-Vance, M. A. (2003). Factor analysis of restricted and repetitive behaviors in autism using the Autism Diagnostic Interview-R. Child Psychiatry and Human Development, 34, 3-17.

Cuskelly, M. (2004). The Evolving Construct of Intellectual Disability: Is everything old new again? International Journal of Disability, Development and Education, 51(1), 117-122.

Dawson, G., \& Adams, A. (1984). Imitation and social responsiveness in autistic children. Journal of Abnormal Child Psychology, 12(2), 209-226.

Dawson, G., \& Galpert, L. I. E. (1986). A developmental model for facilitating the social behavior of autistic children. In E. Schopler \& G. B. Mesibov (Eds.), Social behavior in autism (pp. 237-261). New York: Plenum Press. 
De Boo, G. M., \& Prins, P. J. M. (2007). Social incompetence in children with ADHD: Possible moderators and mediators in social-skills training. Clinical Psychology Review, 27, 7897.

Dissanayake, C., \& Sigman, M. (2001). Attachment and emotional responsiveness in children with autism. . International Review of Research in Mental Retardation, 23, 239-266.

Dodge, K. (1983). Behavioral antecedents of social status. Child Development, 54, 1386-1399.

Dodge, K. A, Lansford, J. E., Burks, V. S., Bates, J. E., Pettit, G. S., Fontaine, R., \& Price, J. M. (2003). Peer rejection and social information-processing factors in the development of aggressive behavior problems in children. Child Development, 74, 374-393.

Fancher, R. E. (1985). The intelligence men: Makers of the IQ controversy. New York: W. W. Norton.

Farroni, T., Massaccesi, S., Menon, E., \& Johnson, M. H. (2007). Direct gaze modulates face recognition in young infants. Cognition, 102, 396-404.

Feldman, R. S. (2006). Development across the lifespan. Upper Saddle River, NJ: Pearson Education, Inc.

Fiske, A. P. (1991). The cultural relativity of selfish individualism: Anthropological evidence that humans are inherently sociable. Prosocial behavior. In M. S. Clark (Ed.), Prosocial behavior, Review of personality and social psychology (Vol. 12, pp. 176-214). Thousand Oaks, CA: Sage Publications, Inc.

Fombonne, E. (2009). Epidemiology of Pervasive Developmental Disorders. Pediatric Research, 65(6), 591-598.

Freedman, B. J., Rosenthal, L., Donahoe, C., Schlundt, D., \& McFall, R. M. (1979). A socialbehavioral analysis of skill deficits in delinquent and nondelinquent adolescent boys. Journal of Consulting and Clinical Psychology, 46, 1448-1462.

Freeman, B. J., Del'Homme, M., Guthrie, D., \& Zhang, F. (1999). Vineland adaptive behavior scale scores as a function of age and initial IQ in 210 autistic children. Journal of Autism and Developmental Disorders, 29, 379-384.

Frith, U. (2004). Emanuel Miller lecture: Confusions and controversies about Asperger's syndrome. Journal of Child Psychology and Psychiatry, 45(4), 672-686.

Ghaziuddin, M., Ghaziuddin, N., \& Greden, J. (2002). Depression in persons with autism: implications for research and clinical care. Journal of Autism and Developmental Disorders, 32, 299-306.

Ghaziuddin, M., \& Zafar, S. (2008). Psychiatric comorbidity of adults with autism spectrum disorders. Clinical Neuropsychiatry, 5, 9-12. 
Gifford-Smith, M. E., \& Brownell, C.A. (2003). Childhood peer relationships: Social acceptance, friendships, and peer networks. Journal of School Psychology, 41, 235-284.

Goddard, H. H. (1910). Four hundred feeble-minded children classified by the Binet method. Journal of Genetic Psychology, 17, 387-397.

Goddard, H. H. (1912). The Kallikak family: A study in the heredity of feeble-mindedness. New York: Macmillan.

Goldstein, T. R., Miklowitz, D. J., \& Mullen, K. L. (2006). Social skills knowledge and performance among adolescents with bipolar disorder. Bipolar Disorder, 8, 350-361.

Goodwin, C. J. (2008). A History of Modern Psychology (3rd ed.). Hoboken, NJ: John Wiley \& Sons, Inc.

Greenspan, S. (1999). What is meant by mental retardation? International Review of Psychiatry, $11,6-18$.

Gresham, F., \& Elliot, S. (1990). Social Skills Rating System. Circle Pines, MN: American Guidance Service.

Gresham, F., Elliott, S., Cook, C., Vance, M. J., \& Kettler, R. (2010). Cross-informant agreement for ratings for social skill and problem behavior ratings: An investigation of the Social Skills Improvement System--Ratings Scales. Psychological Assessment, 22(1), 157-166.

Grossman, T., \& Johnson, M. H. (2007). The development of the social brain in human infancy. European Journal of Neuroscience, 25, 909 - 919.

Hagberg, B., Aicardi, J., Dias, D., \& Ramons, O. (1983). A progressive syndrome of autism, dementia, ataxia, and loss of purposeful hand use in girls: Rett's syndrome: Report of 35 cases. Annals of Neurology, 14, 471-479.

Halgin, R. P., \& Whitbourne, S. (2007). Abnormal Psychology: Clinical Perspective on Psychological Disorders (5 ed.). New York, NY: McGraw-Hill

Heber, R. (1959). A manual on terminology and classification in mental retardation. Washington, D.C.: American Association on Mental Deficiency.

Helsel, W. J., \& Matson, J. L. (1984). The assessment of depression in children: The internal structure of the Child Depression Inventory (CDI) and its relationship to the Matson Evaluation of Social Skills with Youngsters (MESSY). Behavior Research and Therapy, 22, 289-298.

Hobbs, S. A., Walle, D. L., \& Hammersly, G. A. (1984). Assessing children's social skills: Validation of the Behavioral Assertiveness Test for Children (BAT-C). Journal of Psychopathology and Behavioral Assessment, 6, 29-35. 
Hobson, R.P. (1986). The autistic child's appraisal of expressions of emotions. Journal of Child Psychology and Psychiatry, 27, 321-327.

Howlin, P. (1986). An overview of social behavior in autism. In E. Schopler \& G. B. Mesibov (Eds.), Social behavior in autism (pp. 103-126). New York: Plenum Press.

Howlin, P. (2006). Autism spectrum disorder. Psychiatry, 5(9), 320-324.

Jacobson, N. S., \& Truax, P. (1991). Clinical significance: A statistical approach to defining meaningful change in psychotherapy research. Journal of Consulting and Clinical Psychology, 59, 12-19.

Jou, R. J., Minshew, N. J., Keshavan, M. S., \& Hardan, A. Y. (2010). Cortical gyrification in autistic and Asperger disorders: A preliminary magnetic resonance imaging study. Journal of Child Neurology, 25, 1462-1467.

Kaland, N. (2011). Brief Report: Should Asperger syndrome be excluded from the forthcoming DSM-V. Research in Autism Spectrum Disorders, 5(3), 984-989.

Kaland, N., Moller-Nielsen, A., Callesen, K., Mortensen, E. L., Gottlieb, D., \& Smith, L. (2002). An 'advanced' test of theory of mind: Evidence from children and adolescents with Asperger syndrome. Journal of Child Psychology and Psychiatry, 43, 517-528.

Kanner, L. (1943). Autistic disturbances of affective contact. Nervous Child, 2, 217-230.

Kanner, L. (1965). Infantile autism and the schizophrenias. Behavioral Science, 4, 412-420.

Kevles, D. J. (1968). Testing the Army's intelligence: Psychologists and the military in World War I. Journal of American History, 55, 565-581.

Klin, A., Saulnier, C. A., Sparrow, S. S., Cicchetti, D. V., Volkmar, F.R., \& Lord, C. (2007). Social and communication abilities and disabilities in higher functioning individuals with autism spectrum disorders: The Vineland and the ADOS. Journal of Autism and Developmental Disorders, 37, 748-759.

Klin, A., Sparrow, S.S., Volkmar, F.R., Cicchetti, D.V., and Rourke, B.P. (1995). Asperger syndrome. In B.P. Rourke (Ed.), Syndrome of nonverbal learning disabilities: Neurodevelopmental manifestations. New York: Guilford Press.

Kolvin, I. (1971). Psychosis in childhood: A comparative study. In M. Rutter (Ed.), Infantile autism: Concepts, characteristics, and treatment. London: Churchill-Livingstone.

Kovacs, M., \& Goldston, D. (1991). Cognitive and social cognitive development of depressed children and adolescents. Journal of the American Academy of Child and Adolescent Psychiatry, 30, 388-392. 
Krauss, M. W., Gulley, S., Sciegaj, M., \& Wells, N. (2003). Access to specialty medical care for children with mental retardation, autism, and other special health care needs. Mental Retardation, 41, 329-339.

Leonard, H., \& Wen, X. (2002). The epidemiology of mental retardation: Challenges and opportunities in the new millennium. Mental Retardation and Developmental Disabilities Research Reviews, 8(3), 117-134.

Luckasson, R., Coulter, D. L., Polloway, E. A., Reese, S., Schalock, R. L., Snell, M. E.,... Stark, J. A. (1992). Mental retardation: Definition, classification, and systems of supports (9th ed.). Washington, DC: American Association on Mental Retardation.

Mallinckrodt, B., McCreary, B. A., \& Robertson, A. K. (1995). Co-occurrence of eating disorders and incest: the role of attachment, family environment, and social competencies. Journal of Counseling Psychology, 42, 178-186.

Matson, J. L. (1988). The Matson Evaluation of Social Skills with Youngsters (MESSY). Worthington, Ohio: International Diagnostic Symptoms.

Matson, J. L. (2010). The Matson Evaluation of Social Skills with Youngsters-II (MESSY-II). Baton Rouge, LA: Disability Consultants, LLC.

Matson, J. L., \& Barrett, R. P. (1982). Psychopathology in the mentally retarded. New York: Grune \& Stratton.

Matson, J. L., \& Boisjoli, J. (2008). Strategies for assessing Asperger's syndrome: A critical review of data based methods. Research in Autism Spectrum Disorders, 2, 237-248.

Matson, J. L., Dempsey, T., \& Fodstad, J. C. (2009). The effect of autism spectrum disorders on adaptive independent living skills in adults with severe intellectual disability. Research in Developmental Disabilities, 30, 1203-1211.

Matson, J. L., Gonzales, M. L., Wilkins, J., \& Rivet, T. T. (2008). Reliability of the Autism Spectrum Disorder-Diagnostic for Children (ASD-DC). Research in Autism Spectrum Disorders, 2(3), 533-545.

Matson, J. L., Heinze, A., Helsel, W. J., Kapperman, G., \& Rotatori, A. F. (1986). Assessing social behaviors in the visually handicapped: The Matson Evaluation of Social Skills with Youngsters (MESSY). Journal of Clinical Child Psychology, 15, 78-87.

Matson, J. L., Horovitz, M., Mahan, S., \& Fodstad, J. C. (2010). Reliability of the Matson Evaluation of Social Skills with Youngsters for children with Autism Spectrum Disorders. Research in Autism Spectrum Disorders.

Matson, J. L., Kozlowski, A. M., Neal, D., Worley, J. A., \& Fodstad, J. C. (2011). Cutoffs for the Matson Evaluation of Social Skills for Youngsters-II (MESSY-II) for typically 
developing children and for children diagnosed with autism spectrum disorders. Research in Autism Spectrum Disorders, 5, 798-802.

Matson, J. L., Macklin, G. F., \& Helsel, W. J. (1985). Psychometric properties of the Matson Evaluation of Social Skills with Youngsters (MESSY) with emotional problems and selfconcept in deaf children. Journal of Behavior Therapy and Experimental Psychiatry, 14, 117-123.

Matson, J. L., \& Minshawi, N. F. (2006). Early intervention for autism spectrum disorders: A critical analysis. Oxford, England: Elsevier Science, Inc.

Matson, J. L., Neal, D., Hess, J. A., Fodstad, J. C., Mahan, S., \& Rivet, T. T. (2010). Reliability and validity of the Matson Evaluation of Social Skills with Youngsters (MESSY). Behavior Modification, 34, 539-558.

Matson, J. L., \& Nebel-Schwalm, M. (2007). Assessing challenging behaviors in children with autism spectrum disorders: A review. Research in Developmental Disabilities, 28, 567579.

Matson, J. L., \& Ollendick, T. H. (1988). Enhancing children's social skills: Assessment and training (Japanese translation). Tokyo: UNI Agency Inc.

Matson, J. L., Rotatori, A. F., \& Helsel, W. J. (1983). Development of a rating scale to measure social skills in children: The Matson evaluation of social skills with youngsters (MESSY). Behavior Research Therapy, 21, 1203-1211.

Matson, J.L., Smiroldo, B.B., \& Bamburg, J.W. (1998). The relationship of psychopathology to social skills in persons with severe and profound mental retardation. Journal of Intellectual Disability Research, 23, 137-145.

Matson, J. L., Stabinsky-Compton, L. S., \& Sevin, J. A. (1991). Comparison and item analysis of the MESSY for autistic and normal children. Research in Developmental Disabilities, 12, 361-369.

Matson, J. L., Taras, M. E., Sevin, J. A., Love, S. R., \& Fridley, D. (1990). Teaching self-help skills to autistic and mentally retarded children. Research in Developmental Disabilities, 11, 361-378.

Matson, J. L., \& Wilkins, J. (2007). A critical review of assessment targets and methods for social skills excesses and deficits for children with autism spectrum disorders. Research in Autism Spectrum Disorders, 1, 28-37.

Matson, J. L., \& Wilkins, J. (2008). Reliability of the Autism Spectrum Disorder - Comorbid for Children (ASD-CC). Journal of Developmental and Physical Disabilities, 20, 327-336.

Matson, J. L., \& Wilkins, J. (2009). Psychometric testing methods for children's social skills. Research in Developmental Disabilities, 30, 249-274. 
McClelland, M. M., Morrison, F. J., \& Holmes, D. H. (2000). Children at-risk for early academic problems: The role of learning-related social skills. Early Childhood Research Quarterly, 15, 307-329.

McClelland, M. M., \& Scalzo, C. (2006). Social Skills Deficits. In M. Hersen (Ed.), Clinician's Handbook of Child Behavioral Assessment (pp. 313-335). Forest Grove, Oregon: Elsevier.

McFall, R. M. (1982). A review and reformulation of the concept of social skills. Behavioral Assessment, 4, 1-33.

McFall, R. M., \& Marston, A. R. (1970). An experimental investigation of behavior rehearsal in assertiveness training Journal of Abnormal Psychology, 76, 295-303.

Mendez, F. X., Hildalgo, M. D., \& Ingles, C. J. (2002). The Matson Evaluation of Social Skills with Youngsters: Psychometric properties of the Spanish translation in the adolescent population. European Journal of Psychological Assessment, 18, 30-42.

Michelson, L., DiLorenzo, T. M., Calpin, J. P., \& Ollendick, T. H. (1982). Situational determinants of the Behavioral Assertiveness Role-Play Test for Children. Behavior Therapy, 13, 724-734.

Ming, X., Brimacombe, M., Chaaban, J., Zimmerman-Bier, B., \& Wagner, G. C. (2008). Autism spectrum disorders: concurrent clinical disorders. Journal of Child Neurology, 32, 6-13.

Montes, G., \& Halterman, J. S. (2007). Bullying among children with autism and the influence of comorbidity with ADHD: A population-based study. Ambulatory Pediatrics, 7, 253-257.

Newcomb, A.F., Bukowski, W.M., \& Pattee, L. (1993). Children's peer relations: A metaanalytic review of popular, rejected, neglected, controversial, and average sociometric status. Psychological Bulletin, 113, 99-128.

Newton, J. H., McIntosh, D. E., Dixon, F., Williams, T., \& Youman, E. (2008). Assessing giftedness in children: Comparing the accuracy of three shortened measures of intelligence to the Stanford-Binet Intelligence Scales, Fifth Edition. Psychology in the Schools, 45(6), 523-536.

Parker, J. \& Gottman, J. (1989). Social and emotional development in a relational context: Friendship interaction from early childhood to adolescence. In T. Berndt \& G. Ladd (Eds.), Peer relationships in child development. Wiley series on personality processes (pp. 95-131). New York: Wiley.

Pearlman-Avnion, S., \& Eviator, Z. (2002). Irony understanding preservation in nonverbal learning disabilities. Haifi, Israel: University of Haifa.

Prins, P. J. M. (1997). Dutch version of the Matson Evaluation of Social Skills with Youngsters. University of Amsterdam, Unpublished manuscript. 
Quiggle, N. L., Garber, J., Panak, W. F., \& Dodge, K. A. (1992). Social Information processing in aggressive and depressed children. Child Development, 63, 1305-1320.

Raymond, K. L., \& Matson, J. L. (1989). Social skills in the hearing impaired. Journal of Clinical Child Psychology, 18, 247-258.

Reichow, B., \& Volkmar, F. R. (2010). Social skills interventions for individuals with autism: Evaluation for evidence-based practices within a best evidence synthesis framework. Journal of Autism and Developmental Disorders, 40, 149-166.

Reynolds, C. R., \& Kamphaus, R. W. (2006). BASC-2: Behavior Assessment System for Children, Second Edition. Upper Saddle River, NJ: Pearson Education, Inc.

Ritvo, E. R., \& Freeman, B. J. (1977). National society for autistic children definition of the syndrome of autism. Journal of Pediatric Psychology, 2(4), 146-148.

Ritvo, E. R., \& Freeman, B. J. (1978). National society for autistic children definition of the syndrome of autism. Journal of Autism and Childhood Schizophrenia, 8, 162-169.

Roid, G. (2003a). Stanford-Binet Intelligence Sale--Fifth Edition, Technical Manual. Rolling Meadows, Illinois: Riverside Publishing.

Roid, G. (2003b). Stanford-Binet Intelligence Scales, Fifth Edition (SB5). Itasca, Illinois: Riverside Publishing.

Rutter, M. (1972). Childhood schizophrenia reconsidered Journal of Autism and Childhood Schizophrenia, 2(4), 315-337.

Rutter, M. (1978). Diagnosis and definition of childhood autism. Journal of Autism and Childhood Schizophrenia, 8, 139-161.

Rutter, M., \& Bartak, L. (1971). Causes of infantile autism: Some considerations from recent research. Journal of Autism and Childhood Schizophrenia, 1(1), 20-32.

Schatz, J., \& Hamdan-Allen, G. (1995). Effects of age and IQ on adaptive behavior domains for children with autism. Journal of Autism and Developmental Disorders, 25(1), 51-60.

Schreibman, L. (2005). The science and fiction of autism. Cambridge, MA: Harvard University Press.

Segrin, C. (2000). Social skills deficits associated with depression. Clinical Psychology Review, 20, 379-403.

Segrin, C., \& Taylor, M. (2007). Positive interpersonal relationships mediate the association between social skills and psychological well-being. Personality and Individual Differences, 43, 637-646. 
Sharma, S., Sigafoos, J., \& Carroll, A. (2000). Social skills assessment of Indian children with visual impairments. Journal of Visual Impairments and Blindness, 94, 172-176.

Shevell, M. (2008). Global developmental delay and mental retardation or intellectual disability: Conceptualization, Evaluation, and Etiology. Pediatric Clinics of North America, 55(5), 1071-1084.

Sirios, S., \& Jackson, I. (2007). Social cognition in infancy: A critical review of research on higher order abilities. European Journal of Developmental Psychology, 4, 46-64.

Spence, S. H., Donovan, C., \& Brechman-Toussaint, M. (1999). Social skills, social outcomes, and cognitive features of childhood social phobia. Journal of Abnormal Psychology, 108, 211-221.

Spitzer, R. L., \& Siegel, B. (1990). The DSM-III-R Field Trial of Pervasive Developmental Disorders. Journal of the American Academy of Child and Adolescent Psychiatry, 29(6), 855-862.

Stone, W., \& La Greca, A. (1986). The development of social skills in children. In E. Schopler \& G. B. Mesibov (Eds.), Social behavior in autism (pp. 35-60). New York: Plenum Press.

Strauss, C. C., Lease, C. A., Kazdin, A. E., Dulcan, M. K., \& Last, C. G. (1989). Multimethod assessment of the social competence of children with anxiety disorders. Journal of Clinical Child Psychology, 18, 184-189.

Striano, T., \& Vaish, A. (2006). Seven- to 9-month-old infants use facial expressions to interpret others' actions. The British Psychological Society, 24, 753-760.

Sullivan, H. (1953). The interpersonal theory of psychiatry. New York: Norton.

Szatmari, P., Georgiades, S., Bryson, S., Zwaigenbaum, L. Roberts, W., Mahoney, W., Golberg, J., \& Tuff, L. (2006). Investigating the structure of the restricted, repetitive behaviours and interests domain of autism. Journal of Child Psychology and Psychiatry, 47, 582590.

Tani, M., Kanai, C., Ota, H., Yamada, T., Watanabe, H., Yokoi, H....Iwanami, A. (2012). Mental and behavioral symptoms of person's with Asperger's syndrome: Relationships with social isolation and handicaps. Research in Autism Spectrum Disorders, 6, 907-912.

Terman, L. M. (1925). Genetic studies of genius: Vol. 1: Mental and physical traits of a thousand gifted children. Stanford, CA: Stanford University Press.

The Psychological Corporation. (2002). WPPSI-III Technical and Interpretive Manual. San Antonio, TX: Harcourt Assessment. 
Thomas, L. A., De Bellis, M. D., Graham, R., \& LaBar, K. S. (2007). Development of emotional facial recognition in late childhood and adolescence. Developmental Science, 10, 547558.

Thorndike, E. L. (1920). Intelligence and its uses. Harper's Magazine, 227-235.

Tsakanikos, E., Costello, H., Holt, G., Bouras, N., Sturmey, P., \& Newton, T. (2006). Psychopathology in adults with autism and intellectual disability. Journal of Autism and Developmental Disorders, 36, 1123-1129.

Van Hasselt, V. B., Hersen, M., \& Bellack, A. S. (1981). The validity of role play tests for assessing social skills in children. Behavior Therapy, 12, 202-216.

Vasil'ová, K., \& Baumğartner, F. (2004). Why is social intelligence difficult to measure? Retrieved from http://www.saske.sk/cas/4-2005/studia_vasilova_baumgartner.html

Verté, S., Roeyers, H., \& Buysse, A. (2003). Behavioural problems, social competence and selfconcept in siblings of children with autism. Child: Care, Health and Development, 29, 193-205.

Volkmar, F. R. (1987). Social Development. In D. J. Cohen, A. M. Donnellan \& R. Paul (Eds.), Handbook of autism and pervasive developmental disorders New York: John Wiley and Sons, Inc.

Volkmar, F. R., Carter, A., Grossman, J., \& Klin, A. (1997). Social development in autism. In D. J. Cohen \& F. R. Volkmar (Eds.), Handbook of Autism and Pervasive Developmental Disorders 2nd Edition (pp. 173-194). New York: John Wiley \& Sons, Inc.

Volkmar, F. R., \& Klin, A. (2005). Issue in the classification of autism and related conditions. In F. R. Volkmar, R. Paul, A. Klin \& D. J. Cohen (Eds.), Handbook of autism and pervasive developmental disorders (3rd ed., Vol. 1, pp. 5-41). Hoboken, NJ: John Wiley and Sons.

Wenzel, A., Graff-Dolezal, J., Macho, M., \& Brendle, J. R. (2005). Communication and social skills in socially anxious and nonanxious individuals in the context of romantic relationships. Behaviour Research and Therapy, 43, 505-519.

Wechsler, D. (2002). Wechsler Preschool and Primary Scale of Intelligence-Third Edition (WPPSI-III). San Antonio, TX: Harcourt Assessment.

Wechsler, D. (2003). Wechsler Intelligence Scale for Children-4th Edition (WISC-IV). San Antonio, TX: Harcourt Assessment.

Wehmeier, P. M., Schacht, A., \& Barkley, R. A. (2010). Social and emotional impairment in children and adolescents with ADHD and the impact on quality of life. Journal of Adolescent Health, 46, 209-217.

White, S.W., Keonig, K., and Scahill, L. (2007). Social skills development in children with 
autism spectrum disorders: A review of the intervention research. Journal of Autism and Developmental Disorders, 32, 1858-1868.

Whitehall, M. B., Hersen, M., \& Bellack, A. S. (1980). A conversation skills training program for socially isolated children: An analysis of generalization. Behaviour Research and Therapy, 18, 217-225.

Wilkins, J. \& Matson, J.L. (2007). Social Skills. In J.L. Matson \& L.M. Glidden (Eds.), International Review of Research in Mental Retardation, Vol. 34. Waltham, MA: Academic Press.

Williams, T. I. (1989). A social skills group for autistic children. Journal of Autism and Developmental Disorders, 19, 143-155.

Williamson, D. A., Moody, S. C., Granberry, S. W., Lethermon, V. R., \& Blouin, D. C. (1983). Criterion-related validity of a role-play social skills test for children. Behavior Therapy, $14,466-481$.

Wing, L. (1981). Asperger's syndrome: A clinical account. Psychological Medicine, 11, 115-129.

Wing, L., \& Gould, J. (1979). Severe impairments of social interaction and associated abnormalities in children: epidemiology and classification. Journal of Autism and Developmental Disorders, 9(1), 11-29.

Wing, L., Gould, J., \& Gillberg, C. (2011). Autism spectrum disorders in the DSM-V: Better or worse than the DSM-IV? Research in Developmental Disabilities, 32, 768-773.

Wing, L., \& Potter, D. (2002). The epidemiology of autism spectrum disorders: is the prevalence rising? Mental Retardation and Developmental Disabilities Research Reviews, 8, 151161.

WISC-IV Technical Manual \#2. (2003). The Psychological Corporation, a Harcourt Assessment Company.

Wissler, C. (1965). Clark Wissler (1870-1947) on the inadequacy of mental tests. In R. J. Herrnstein \& E. G. Boring (Eds.), A sourcebook in the history of psychology (pp. 442445). Cambridge, MA: Harvard University Press.

World Health Organization. (1977). International Classification of Diseases (9th ed.). Geneva, Switzerland.

World Health Organization. (1992). International classification of diseases (10th ed.). Geneva, Switzerland: World Health Organization.

Yirmiya, N., \& Sigman, M. (1991). High functioning individuals with autism: Diagnosis, empirical findings, and theoretical issues. Clinical Psychology Review, 11, 669-683. 
Zalla, T., Barlassina, L., Buon, M., \& Leboyer, M. (2011). Moral judgment in adults with autism spectrum disorders. Cognition, 121(1), 115-126. 


\section{APPENDIX}

Project Report and Continuation Application (Complete and return to IRB, 203-B1 David Boyd Hall. Direct questions to IRB Chairman Robert Mathews 578-8692.)

IRB\#: 2609 Your Current Approval Expires On: 11/15/2011 Review type: Expedited Risk Factor: Minima PI: Johnny Matson Dept: Psychology Phone: (225) 578-8745 Student/Co-Investigator: Project Title: Developing the Autism Spectrum Disorder (ASD) Number of Subjects Authorized: 2000

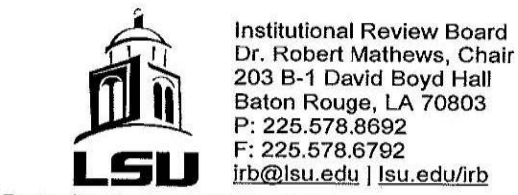

Date Sent: August 11, 2011

Please read the entire application. Missing information will delay approvall

I. PROJECT FUNDED BY: National Institutes of Health LSU proposal \#: $\underline{0}$

II. PROJECT STATUS: Check the appropriate blank(s); and complete the following: DI

$X$ 1. Active, subject enrollment continuing; \# subjects enrolled: 250600

2. Active, subject enrollment complete; \# subjects enrolled:

3. Active, subject enroliment complete; work with subjects continues.

4. Active, work with subjects complete; data analysis in progress.

5. Project start postponed

6. Project complete; end date

7. Project cancelled: no human subjects used.

III. PROTOCOL: (Check one).

X Protocol continues as previously approved

Changes are requested*

- List (on separate sheet) any changes to approved protocol.

IV. UNEXPECTED PROBLEMS: (did anything occur that increased risks to participants):

State number of events since study inception: 0 since last report: $O$

$>\quad$ If such events occurred, describe them and how they affect risks in your study, in an attached report. Have there been any previously unreported events? $Y / N N$ ?

(if YES, attach report describing event and any corrective action).

V. CONSENT FORM AND RISKIBENEFIT RATIO:

Does new knowledge or adverse events change the risk/benefit ratio? $Y / N N$.

Is a corresponding change in the consent form needed? Y/N N

VI. ATTACH A BRIEF, FACTUAL SUMMARY of project progress/results to show continued participation of subjects is justified; or to provide a final report on project findings.

VII. ATTACH CURRENT CONSENT FORM (only if subject enrollment is continuing); and check the appropriate blank

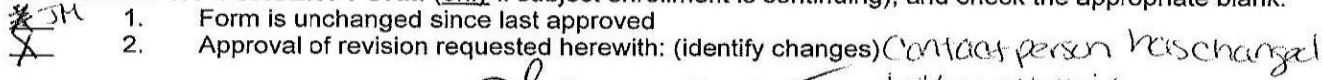

Signature of Principal Investigator:
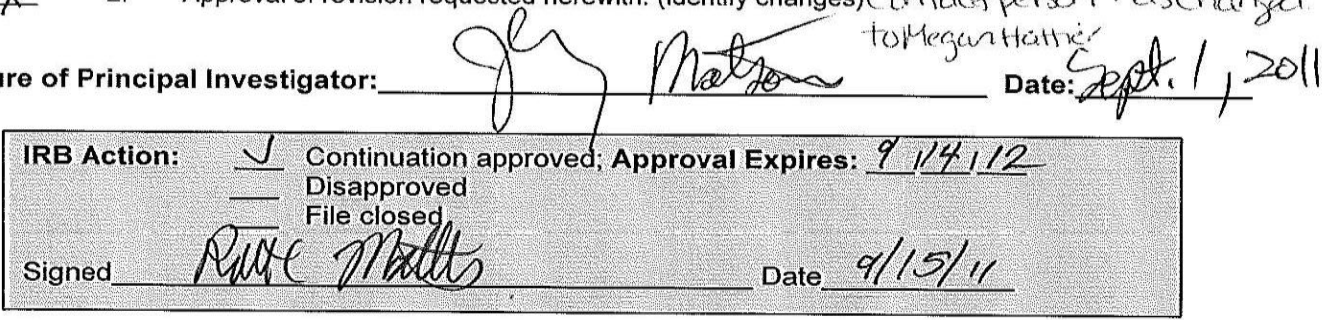

Form date: April 16, 2008 
1. Study Title: Developing the Autism Spectrum Disorder (ASD)

2. Performance Sites: Louisiana State University Psychological Services Center, preschools, grade schools, churches, hospitals or outpatient clinics, organizations, and internet websites.

3. Contacts: Johnny L. Matson, Ph.D. (225) 578-8745 Mon-Fri

4. Purpose of the Study: Several diagnostic instruments exist that are designed to determine the presence of emotional difficulties and behavior problems in children and adults. Currently, there are no screening instruments that incorporate differential diagnosis of the developmental disorders. The purpose of this study is to develop assessment instruments designed to examine the social skills, challenging behaviors, and symptoms of emotional difficulties in children, as well as autistic traits in adults.

5. Subjects: Inclusion Criteria: Parents of children who are $\leq 18$ years old receiving services at the Psychological Services Center; children who are receiving inpatient or outpatient medical/behavioral services, or currently attending preschools, grade schools, or church groups; children recruited via websites or organizations such as those for children with ASD or disabilities; and adults residing in the community. Exclusion Criteria: Parents, legal guardians, or informants unable or unwilling to provide informed consent or parental consent. Maximum number of subjects: 2000

6. Study Procedures: Assessment instruments designed to examine the social skills, challenging behaviors, and symptoms of emotional difficulties in individuals will be administered to the sample of 2000 adult participants (i.e., parents of child participants). Participants will receive information about the study and given an opportunity to volunteer through informational mail-outs at their child's school, church, or clinic, etc. or information given to them when calling about services at the Psychological Services Center. Once consent is granted, participants will be given assessment packets regarding the following either in person at the outpatient clinic, mail, or lnternet link. Participants will provide information regarding the individual's: 1) demographics (e.g., age, gender, ethnicity, parents' names, number of siblings, etc.); 2) current psychotropic drug use and diagnoses; 3) developmental milestones; 4) social skills (e.g., turns head toward caregiver, initiates verbal communication, complains often, prefers to be alone, disturbs others, interacts positively with others, etc.); 5) challenging behavior (i.e., circumstances which the target behavior occurs); and 6) symptoms of other difficulties (e.g., tantrums, excessive worry or concern, initiates fights, fidgets or squirms excessively, stereotypies, intellectual disability, impaired social interactions, has odd gait when running, language delays, etc.). Participants who receive the packet via mail will receive a follow-up phone call to ensure that they have received the packet and have the opportunity to ask questions. This study will take approximately 1 hour to 1.5 hours for each participant. Additionally, children (recruited from the outpatient clinic) of a subset of the sampled adult participants (i.e., parents of child participants) will be administered an abbreviated assessment of intellectual functioning.

7. Benefits: Participants under the age of 18 years may benefit from this study by taking advantage of reduced price assessment services at the Psychological Services Clinic in Baton Rouge, Louisiana. If participants decide to take advantage of this offered benefit, participants will be required to come into the clinic to complete a parent interview and child observation session. If further assessment services are recommended, the participant may receive these services at half of the normal fee. All treatment services will be full price. Further, participants may benefit from professionals developing more reliable and valid assessment measures, suggesting improved diagnostic capabilities and more effective treatment interventions.

8. Risks/Discomforts: There is a small possibility of disclosure of personal information associated with this study. There are no other known risks resulting from participating in this study. Risks experienced should be those limited to those commonly experienced when receiving services from a public mental health clinic.

9. Measures taken to reduce risk: All participants will be given participant numbers. All data collected will be stored in reference to this number only. There will be one (1) master list which will list patient number by participant number to provide a means by which participants can chose to remove their data from the data set after participation. This list will be the only means by which data collected can be linked to personal information such as name or patient number. This list will be stored in a locked file cabinet, separately from the data collected.

10. Right to Refuse: Participation is voluntary. Participants may change their mind and withdraw from the study at any time before the conclusion of the study without penalty or loss of any benefit to which they may otherwise be entitled.

11. Privacy: This study is confidential. Data will be kept confidential unless release is legally compelled.

12. Financial Information: There is no cost to the participant and no payment will be provided for participation.

13. Withdrawal: There are no consequences for terminating participation in this study, which will last approximately 1 hour and 30 minutes in duration for each participant. To withdraw from the study, participants must inform the principle investigator of their desire to do so before the end date of the study. 
14. Removal: A participant's data may be removed from the study if it is discovered that there were errors in the administration of any measure for that particular participant.

\section{ASD Consent Form-Detach this page, Complete, and Return}

The study has been described to me and all my questions have been answered. I may direct additional questions regarding study specifics to the investigators by contacting Megan Hattier at 225-578-1494 or asdlsu@gmail.com.

If I have questions about subjects' rights or other concerns, I can contact Robert C. Mathews, Chairman, LSU Institutional Review Board, (225) 578-8692. I agree to participate in the study described above and acknowledge the researchers' obligation to provide me with a copy of this consent form if signed by me.

Parent/Guardian/Informant Signature Date

(Please Print Name of Parent/Guardian/Informant)

Signature of Adult Participant (if applicable) Date

(Please Print Name of Adult Participant if applicable)

The participant has indicated to me that he/she is unable to read. I certify that I have read this consent form to the participant and explained that by completing the signature line above he/she has given permission to participate in the study.

Signature of Reader Date

$* * * * * * * * * * * * * * * * * * * * * * * * * * * * * * * * * * * * * * * * * * * * * * * * * * * * * * * * * * * * * * * * * * * * * * * * * * * * * * * * * * * * * * * * * *$

PLEASE FILL OUT THE FOLLOWING CONTACT INFORMATION:

(A research assistant will contact you to obtain additional information and answer any questions you may have before mailing questionnaires or sending email link to survey)

Telephone number(s) where informant can be reached:

Best time of day to be reached:

Mailing Address:

Email Address:

Circle to indicate your preference for the question below:

INTERNET MAIL Would you prefer to be mailed the questionnaires in paper with a prepaid (electronic) (paper) envelope included OR receive an Internet link via email to the questionnaires to complete the questionnaires electronically on the Internet.

If you answered MAIL (paper), please answer the following additional questions:

YES No $\quad$ 1. Would you be willing to complete a shorter set of similar questions approximately 2 weeks after completing the first?

YES NO 2. Is there a second adult who knows your child well (other parent, 
grandparent, etc.) who would be willing to complete the questionnaires for your child independently from yourself?

YES NO 3. Do you consent to your child's teacher completing a similar set of questionnaires for your child?

Study Approved By:

Dr. Rober C. Mathews, Chairman

Institutional Review Board

Louisiana State University

203 B-1 David Boyd Hall

225-578-8692 | www. Isu.edu/irb

Approval Expires: $9-14-2012$ 


\section{VITA}

Kimberly Tureck was born the daughter of Gary and Ellen Tureck in Madison, New Jersey, in 1988. Following the completion of her Bachelor of Science degree in neuroscience from Union College in 2010, she enrolled in Louisiana State University‘s Clinical Psychology Doctoral Program under the supervision of Dr. Johnny L. Matson. Her clinical and research interests include the assessment and treatment of autism spectrum disorders, intellectual disabilities, and other forms of psychopathology in children. 